\title{
Life-cycle effects of age at school start*
}

\author{
Peter Fredriksson Björn Öckert
}

\begin{abstract}
In Sweden, children typically start compulsory school the year they turn 7. Individuals born around the new year have about the same date of birth but enter school at different ages. We exploit this source of exogenous variation to identify effects of age at school entry on educational attainment and long-run labor market outcomes. Using data for the entire native population born 1935-55, we find that school entry age raises educational attainment. We show that the comprehensive school reform (which postponed tracking until age 16) reduced the effect of school starting age on educational attainment. We also trace the effects of school starting age on prime-age earnings, employment, and wages. On average, school starting age only affects the allocation of labor supply over the lifecycle; prime-age earnings is unaffected, and there is a negative effect on discounted life-time earnings. But for individuals with low-educated parents, and to some extent women, we find that prime-age earnings increase in response to age at school start.
\end{abstract}

JEL-codes: I21, I28, J24, C31

Keywords: School starting age, educational attainment, life-time earnings, regression discontinuity

\section{Introduction}

There is an extensive literature on the relationship between age at school start and in-school performance. The results typically indicate that older school starters do better in school.

\footnotetext{
*This version: March 2013. Fredriksson is affiliated with Stockholm University, the Institute for Evaluation of Labour Market and Education Policy (IFAU), IZA, and the Uppsala Center for Labor Studies (UCLS). Öckert is affiliated with IFAU, Uppsala University, and UCLS. We thank Olof Åslund, Torsten Persson, Steve Pischke, Roope Uusitalo, two anonymous referees, as well as seminar and conference participants at IUI, SOFI, IFAU, FIEF, NTNU, IIES, the Universities of Copenhagen, Göteborg, Helsinki, Montreal, Växjö, EALE/SOLE, the CEPR conference on "Education and Inequality", and the first EEEPE workshop for valuable comments. Financial support from the Marcus and Amalia Wallenberg foundation and Handelsbanken is gratefully acknowledged.
} 
But these results are hard to interpret since older school starters are also older when school performance is measured. In contrast to much of the literature, this paper focuses on the long-run effects of school entry age.

More precisely, we ask the question: How does school starting age affect educational attainment and long-run labor market outcomes? To answer this question we exploit exogenous variation in school starting age due to month of birth and the school entry cut-off date (the 1 st of January). This implies a regression-discontinuity design which we apply to unique Swedish administrative data. The data pertain to the entire native Swedish population born between 1935 and 1955. The data set includes earnings information spanning the entire career of these cohorts as well as educational attainment at age 40-50.

Swedish data are particularly apt for examining the issues addressed in this paper. One advantage is that the compulsory schooling law requires individuals to complete a minimum number of years of education, independently of when they start. Moreover, grade retention or advancement is rarely practiced in Sweden. These two features facilitate the identification of the school starting age effect, since the effect is not contaminated by the variation in years of compulsory schooling. Things are different in, e.g., the U.S. context, where the school leaving age legislation implies that season of birth has an impact on years of compulsory schooling (Angrist and Krueger 1991).

Another advantage is that we have information on earnings from 1960 until 2009. Thus, we can analyze earnings outcomes throughout the career for most cohorts. Previous analyses of school entry age on earnings have either used data for a single point in time for several cohorts (Fredriksson and Öckert 2005 and Dobkin and Ferreira 2010) or panel data covering the ages 24-35 (Black et al. 2011). Relative to Black et al. (2011) our value added is that we extend the analysis beyond age 35. In particular, we estimate the effect of school entry age on prime-age (25-54) earnings for all cohorts. Moreover, some cohorts are observed beyond the nominal retirement age (65) and we calculate the effect on actual life-time earnings. The analysis of earnings outcomes throughout the career is the first major value added of the paper.

A final advantage or our data is that they span cohorts who attended school in different systems. The older cohorts went to school in a selective system with early tracking; the younger cohorts attended a comprehensive system where students were held together. This compulsory school reform was phased in in different parts of the country (Meghir and Palme 2005; Holmlund 2007). This setting lends itself to a differences-in-differences analysis which compares the effect of school starting age on educational attainment across school systems holding cohort constant. This is the second major value added of our paper. Our evidence on 
this point should be more credible than the evidence reported in Bedard and Dhuey (2006) who compared age effects across countries while children are still in school. ${ }^{1}$

Throughout the paper we focus on long-run outcomes. We thus circumvent the fundamental identification problem which occurs when children are still in school. With information on adult outcomes, observed at a given time-point, it is possible to hold age at observation constant and still identify school starting age via the discontinuity around the school entry cut-off. $^{2}$

Our paper is related to an extensive literature. The vast majority of studies examine inschool outcomes (see Stipek 2002 for a survey). For reasons explained above it is hard to interpret the results in this literature as the effect of school starting age. ${ }^{3}$ There is a more recent economics literature on how season of birth and school starting age affect long-run outcomes. The first paper in this vein is Angrist and Krueger (1992) who examined how season of birth affects educational attainment. The paper most similar to ours is the recent analysis by Black et al. (2011). They conclude that the long-run effects on education and earnings are modest.

While we credibly estimate the long-run impacts of school entry age, we have less to offer on the precise mechanism. When it comes to the relationship between age at school start and skill acquisition, the literature has emphasized two kinds of mechanisms: one due to absolute maturity - learning in a school environment is more/less effective at certain ages and another due to relative maturity - being the oldest in class gives an early advantage which may persist in the longer run. ${ }^{4}$ The variation we are using captures both of these mechanisms and we cannot separate them. Note that, even if only relative maturity at school start is relevant, it is likely that the effects will persist for some time. In systems where children are tracked early on it is more likely that early advantages will persist; see Bedard and Dhuey (2006). Since we do not disentangle relative and absolute school starting age effects, our

\footnotetext{
${ }^{1}$ Also, see Muhlenweg and Puhani (2010) for suggestive evidence on the impact of tracking on school entry age effects.

${ }^{2}$ Having said this, we recognize that age at crucial stages of selection may still be important for long-run outcomes. We attribute such effects to school starting age since if children had not started school at different ages, age at the crucial stage of selection would not have varied.

${ }^{3}$ There are some recent attempts to separate school starting age from age at test. These attempts typically rely on functional form assumptions to separate age at observation from age at school start. Two examples are Datar (2006) and Elder and Lubotsky (2009).

${ }^{4}$ Absolute maturity include: theories of "critical periods" where the brain is especially sensitive to specific experiences (Shonkoff and Phillips 2000); and theories emphasizing that young children lack the maturity to learn complicated things in a school environment. Relative maturity include: a theory based on peer quality, where younger children may benefit from being surrounded by older and more able peers; and evidence from psychology where older children respond to early encouragement by pushing to perform even better in the future.
} 
evidence do not speak to the wider policy question of whether school start should be pushed earlier or later.

Our empirical strategy mimics the following decision problem. Consider a parent whose child is born in December. The parent may opt for the normal school start, in which case the child will be the youngest in class, or it may hold back the child a year. If the child is held back, it will have an initial advantage which may result in higher attainment in the longer run. But holding back the child a year, implies forgone earnings for given age. These initial losses should be traded off with the potential for subsequent earnings gains in the future. In our empirical work, we estimate the effects of school starting age on the age-earnings profile and thus provide a sense of the magnitudes of initial losses and subsequent gains (if any).

We find that starting school at older age raises educational attainment. The school starting age effects are more pronounced in the school system featuring earlier tracking. On average, school entry age mainly affect the timing of labor supply over the life-cycle; primeage earnings is unaffected, and there is a negative effect on discounted life-time earnings. For individuals with low-educated parents and, to some extent, women, we document a positive effect on prime-age earnings. These effects are mostly driven by higher probability of working among those who start school at older age.

\section{Compulsory schooling in Sweden}

Compulsory school starts the year the children turns 7 which implies a school entry cutoff date on the 1st of January. Most parents adhere to the rule; moreover, retention and advancement is rarely practiced in Sweden. Data for the 1960s (relevant for the cohorts born in the 1950s) suggest that half of those finishing late (only $3.6 \%$ of the population) were retained during compulsory school.

The cohorts we are studying (the cohorts born 1935-55) were exposed to two different school systems. The older cohorts (basically those born 1935-1945) lived under a rather selective system. In this system, 7 or 8 years of schooling were mandatory, local authorities determined the curriculum, and strict ability tracking was implemented in grade 5 or 7 . Children in different tracks went to different schools; children in the lower tracks had scant opportunities to pursue further education.

In 1950, the parliament decided to introduce a 9-year "comprehensive school" gradually across the country. Whether a municipality (or city community) should implement the reform was determined by the National Board of Education, after an application by the municipality 
(or the city community). ${ }^{5}$ The reform abolished strict tracking and featured a nationally determined curriculum. There was still some tracking in lower secondary school. Importantly, however, students in different tracks attended the same school. Moreover, choosing the lower track did not imply that further educational opportunities were closed. The gradual introduction of the comprehensive school mainly affected the cohorts born between 1945 and 1955 (Holmlund 2007). In the 1945 cohort, 2\% attended the new comprehensive school; in the 1955 cohort this share had increased to $98 \%$.

The older cohorts in our data were also exposed to some reform. In particular, compulsory school could be extended from 7 to 8 years on the decision of the local authorities. This is a reform within the same basic structure of the school system, and hence not as radical as the comprehensive school reform.

The time-period we study is a period where pre-school education was not available. In 1950 , the number of child-care slots could accommodate $1.4 \%$ of the population aged 15. The time-period features a substantial rise in educational attainment. The probability of having at least 2 years of college education increased from 9\% (cohort born 1935) to $17 \%$ (1955 cohort).

\section{Empirical strategy}

For an individual $i$, in cohort $c$, the outcome equation of interest is

$$
y_{i c}=\alpha_{c}+\beta S S A_{i c}+f_{c}^{k}\left(M_{i c}\right)+\varepsilon_{i c}
$$

where SSA denotes age at school start, $M$ month of birth, and the outcomes considered are long-run educational and labor market outcomes. $\alpha_{c}$ denotes a cohort fixed effect, where we define a cohort as running from July to June rather than over year of birth. The school entry cut-off is thus in the middle of a cohort defined in this way. $f_{c}^{k}\left(M_{i c}\right)$ denotes a polynomial control function (of order $k$ ) in the "assignment variable" (month of birth) which is interacted with the cut-off and (potentially) by cohort. Month of birth is normalized to zero around the school entry cut-off and thus $M_{i c}=\{-5.5, \ldots, 5.5\}$.

Since individuals may be selected on (projected) academic ability when starting school, $S S A$ is potentially endogenous. We instrument it using the school entry cut-off. Define the treatment indicator After as

$$
\text { After }_{i c}=I\left(M_{i c}>0\right)
$$

\footnotetext{
${ }^{5}$ City communities are parts of municipalities in the big-cities.
} 
Since $M$ is normalized to zero at the cut-off, After $=1$ for individuals born January to June and 0 otherwise. The first stage equation thus is

$$
S S A_{i c}=\delta_{c}+\gamma \text { After }_{i c}+g_{c}^{k}\left(M_{i c}\right)+v_{i c}
$$

and the reduced form

$$
y_{i c}=\theta_{c}+\lambda \text { After }_{i c}+h_{c}^{k}\left(M_{i c}\right)+\mu_{i c}
$$

In equations (3)-(4): $\delta_{c}$, and $\theta_{c}$ are cohort fixed effects; and $g_{c}^{k}\left(M_{i c}\right)$ and $h_{c}^{k}\left(M_{i c}\right)$ are control functions defined in the same way as $f_{c}^{k}\left(M_{i c}\right)$. The control functions take care of any smooth underlying relationship between month of birth and the outcome of interest. Within cohort, the control functions also hold age at observation constant. Identification is achieved by the discrete jump in school starting age at the cut-off. In particular, children born on each side of the new year have about the same date of birth but differ in their school starting age by almost a year. Since the rule is not completely binding, this is a fuzzy Regression Discontinuity (RD) design.

The assignment variable is discrete; thus, we have to rely on a parametric control function. In these situations, Lee and Card (2008) recommend clustering the standard errors on the discrete values of the assignment variable. We follow their recommendation.

Another complication is that we do not observe $S S A$ and the outcomes in the same data set. This is thus an example of two-sample instrumental variables (Angrist and Krueger 1992). Inoue and Solon (2010) note that the best way to deal with this issue is to view it as a generated regressors problem and use the method proposed by Murphy and Topel (1985) to correct the standard errors. We follow this approach.

The validity of the instrument can be examined in a number of ways. The most straightforward way is to examine whether predetermined characteristics are related to the instrument. But we also check whether the distribution of births around the discontinuity is smooth (see McCrary 2008). In section 5 and in the Appendix we discuss various tests of instrument validity.

The two-stage least squares strategy relies on the assumption that there are no other changes around the cut-off that affects outcomes. A source of concern is that educational reforms typically pertain to year of birth rather than our July/June definition of cohorts. The educational reforms, described in Section 2, added 1-2 years of compulsory education. This is a potential problem since it may mechanically raise educational attainment among those born after the cut-off during the reform year. 
Reform status varies by place of residence and year of birth. Hence we can construct indicators for whether a given individual was subjected to reform. Since place of residence may be endogenous to the reform, we assign reform status on the basis of parish of birth and year of birth. This strategy allows us to address the potential problem caused by the reforms it two ways: first, we hold reform status and birth parish constant, thus controlling for any mechanical effect affecting our key estimate; second, we exclude years when a particular parish reformed. As it turns out it does not matter which approach we use, so the first strategy is our main strategy.

\section{Data}

The data mainly come from administrative records. The administrative data originate from Statistics Sweden and cover the entire population born in Sweden 1935-55. 6 To these data we have matched information on annual earnings, educational attainment, and wages, as well as information on education and employment for the biological parents. Information on year and month of birth originate from birth records and do not suffer from measurement error. All wage and earnings data are in SEK 2009 values.

The earnings data are available 1960-66, 1968, 1970-71, 1973, 1975-76, 1979-80, 1982, 1985-2009. Between 1960 and 1966 the earnings data are available for a 10\% sample (individuals born on the 5th, 15th, and 25th of each month). From 1968 and onwards they are available for the entire population. These data span the entire labor market careers of most cohorts. Individuals in the oldest cohort are observed when they are aged 25-74; individuals in the youngest cohort are observed when they are aged 16-54.

The wage data are available during 1985-2009 and stem from the so-called Wage register. Monthly wages are measured in full-time equivalents and thus analogous to hourly wages; they are collected for those who are employed on a particular day of measurement (in September-November). Using the mapping between wages and earnings for cells defined by the interactions between gender, age, and education we construct indicators of whether individuals are (full-time) employed; the Appendix describes this procedure more fully.

Information on educational attainment is available from the Censuses conducted in 1960, 1970 and 1990, and from the Educational register from 1985 and onwards. As the general rule we use information when the individuals are aged 45 . For the individuals under study, we mainly use the information between 1985 and 2000 and for the parents we use the 1960

\footnotetext{
${ }^{6}$ We exclude all immigrants since they lack reliable information on date of birth, school starting age, and years of schooling.
} 
or 1970 censuses. A small fraction of the sample (2.96\%) have missing information on either the mother or the father; for these individuals we have no information on the education of the parent. We translate educational attainment to years of schooling using information on the typical years of schooling associated with a given attainment level.

School starting age is not reported in our main data set. Instead we use data from "Evaluation Through Follow-up" (ETF), a project run by the Department of Education at the University of Göteborg (see Härnquist 2000). These data, inter alia, contain information for a $10 \%$ sample of the cohort born 1948 (individuals born on the 5th, 15th, and 25th of each month). We estimate the relation between school starting age and birth month in the ETF-data and then predict school starting stage for all cohorts in the main data set.

\section{Validity of the instrument}

A threat to the validity of the RD design is if (certain) parents systematically time their births with respect to the cut-off. Figures 1 and 2 present two pieces of evidence demonstrating that there is no evidence of such behavior. Figure 1 shows that there is no suspect jump in the number of births around the discontinuity. Figure 2 shows that parental education is balanced at the cutoff; the estimated discontinuity is 0.013 years with a standard error of 0.014. Moreover, in the Appendix we show that these conclusions hold up when we use more finely grained birth information, which is not available in the main data.

Table 1 presents further evidence by examining whether gender, parental education, and parental employment are balanced around the cut-off. ${ }^{7}$ To facilitate readability all estimated coefficients (and standard errors) are multiplied by $100 .^{8}$

Column (1) presents the results of regressing the instrument on parental education and gender. In column (2) we add parental employment to the regression. By conditioning on parental employment we loose an additional $12 \%$ of the sample, which is why we present two sets of regression results. ${ }^{9}$ Column (3) adds the educational reform controls.

The $\mathrm{p}$-values, reported in the second row from the end, range from 0.533 to 0.760 . Thus, we do not reject the hypotheses that the covariates are unrelated to the instrument. Column (4)

\footnotetext{
${ }^{7}$ All these characteristics are highly relevant for all outcomes. For instance, mother's who have an additional year of education have children who on average have 0.23 additional years of education (t-ratio: 63.6).

${ }^{8}$ The estimate on Female in the first row of column 1 thus says that the probability of being born after the cutoff is 0.005 percentage points higher for females than for males.

${ }^{9}$ Information on parental employment comes from the censuses in 1960 and 1965. In the strict sense, it is not pre-determined with respect to child birth. We think this is a minor problem. Nevertheless, this is an additional reason for presenting separate regressions.
} 
Figure 1. Distribution of births by birth month

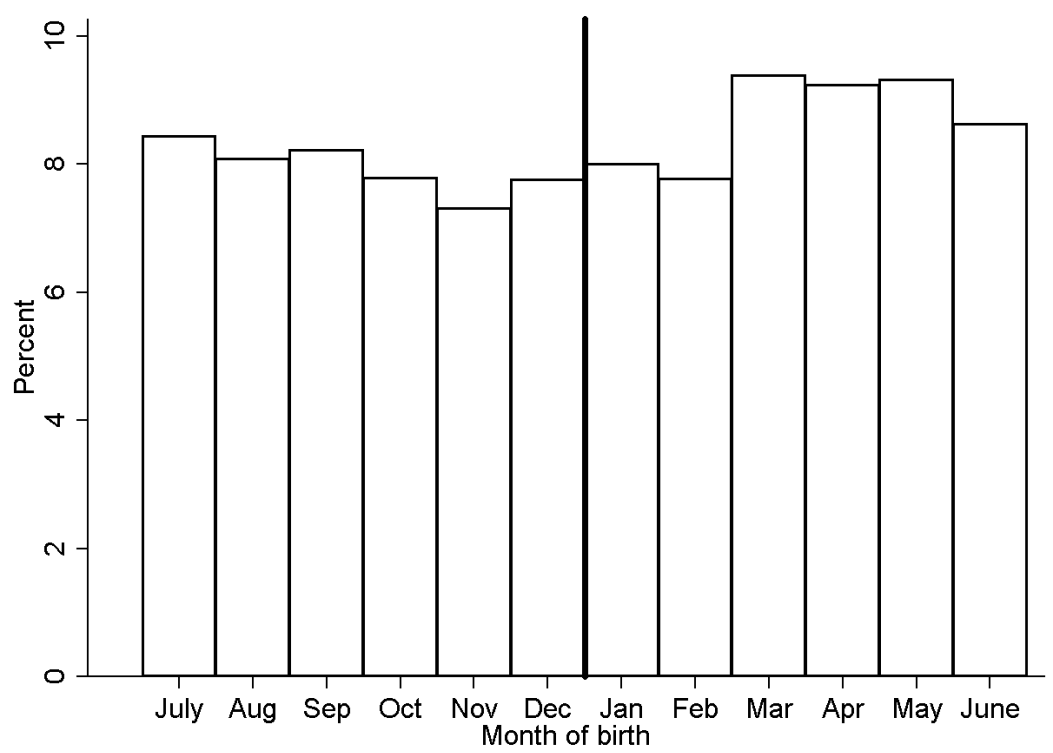

Note: The figure shows the distribution of births by birth month among natives who are born between July 1935 and June 1955

Figure 2. Parental education by month of birth

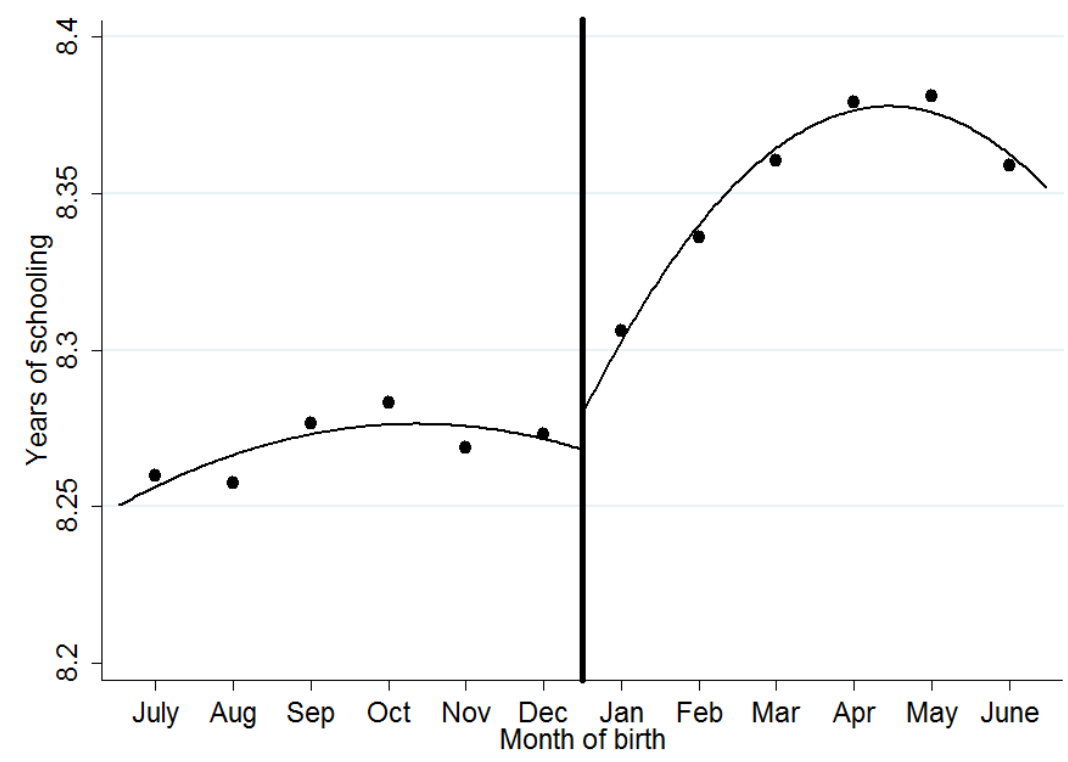

Notes: Parental years of schooling is defined as the maximum of the education of the father or the mother. Discontinuity at cut-off: 0.013 (standard error: 0.014 ). The solid line depicts the school entry cut-off. Regression lines are 2nd order polynomials fitted separately to the individual data on each side of the cut-off. We control for cohort and educational reform (see section 2). 
Table 1. Balancing of covariates

\begin{tabular}{lccc|c}
\hline & \multicolumn{2}{c|}{$\begin{array}{c}\text { Dependent variable: After cut-off } \\
\text { (Coefficient/SE:s mult. by 100) }\end{array}$} & $\begin{array}{c}\text { p-value of } \\
\text { bivariate correlation }\end{array}$ \\
\hline Female & $(1)$ & $(2)$ & $(3)$ & $(4)$ \\
& 0.005 & 0.012 & 0.012 & 0.614 \\
Mother's education & $(0.021)$ & $(0.024)$ & $(0.024)$ & \\
& 0.012 & 0.013 & 0.016 & 0.211 \\
Father's education & $(0.008)$ & $(0.009)$ & $(0.010)$ & \\
& -0.002 & -0.002 & -0.002 & 0.670 \\
Mother employed & $(0.005)$ & $(0.005)$ & $(0.007)$ & \\
& - & -0.007 & -0.012 & 0.856 \\
Father employed & - & $(0.029)$ & $(0.030)$ & \\
& & 0.016 & 0.019 & 0.763 \\
Educational reform controls & & $(0.065)$ & $(0.065)$ & \\
Month of birth controls & & & & $\sqrt{ }$ \\
2nd order & $\sqrt{ }$ & $\sqrt{ }$ & $\sqrt{ }$ & $\sqrt{ }$ \\
Interacted w. cutoff & $\sqrt{ }$ & $\sqrt{ }$ & $\sqrt{ }$ & - \\
p-value of F-test & 0.533 & 0.760 & 0.651 & $1,732,987$ \\
\# individuals & $1,978,242$ & $1,733,070$ & $1,732,987$ & \\
\hline
\end{tabular}

Notes: Coefficients and standard errors are multiplied by 100 to facilitate readability. The regressions are based on individuals born July 1935 to June 1955. They include (20) cohort fixed effects where a cohort include individuals born July/June. The educational reform controls are dummies for the two reforms described in section 2 and birth parish FE:s. Results in column (4) come from separate regressions of the covariate, reported in each row, on the instrument. Standard errors, shown in parentheses, allow for clustering (240 clusters) on the discrete values of the assignment variable. 
adds more evidence on this point by examining the bivariate relation between each individual characteristic and the instrument. Each row in column (4) reports the p-value of a t-test obtained by regressing the characteristic in question on the instrument. Again, we do not reject the hypothesis that each individual characteristic is unrelated to the instrument.

The regression results are based on controlling for a 2nd order polynomial in birth month interacted with the cut-off. ${ }^{10}$ A specification with a first order polynomial (interacted with the cut-off) is inferior to the specification with the 2 nd order polynomial. With a linear interacted control function we reject the hypothesis of no relation between the instrument and the covariates. Adding higher-order polynomials do not change the results. Adding interactions between cohort and the 2 nd order (interacted) polynomial do not change the results either. We therefore conclude that baseline covariates are unrelated to the instrument, given that we control sufficiently flexibly for month of birth.

Figure 3 illustrates the relation between age at school start and birth month in the ETFdata. There is a substantial jump in school starting age around the cut-off. Individuals born just after the school entry cut-off, start when they are 0.86 years older than those born just before the cut-off (the t-ratio is 49.2).

The reason for the strong relationship between SSA is that it was relatively uncommon to start school early or late, even for those born around the cut-off. On average only $2.0 \%$ of the individuals started early while $3.3 \%$ started late. Even though early starts were more common among individuals born in January (7\%), and late starts more common among those born in December (8\%), the overwhelming majority of the individuals born around the cutoff start at the normal time.

Figure 4 shows the probability of starting early and late by birth month and gender. It is more likely that boys start late. The probability that a boy born in December starts late is $9.1 \%$; the corresponding number for girls is $5.6 \%$. This gender difference arguably reflects less maturity among boys around school start. If this is the correct interpretation, one would expect the probability of starting early to be lower among boys. However, there is no such pattern in the data. In fact, the probability that boys born in January start early is $6.8 \%$; the corresponding number for girls is 6.7\%. A similar pattern is true for February (boys 5.4\%; girls 5.1\%). But March is more in line with expectation, i.e., lower for boys $(2.3 \%)$ than for girls (3.6\%). The probability of starting early among boys born just after the cut-off appears to be too high, both relative to boys born slightly later (i.e. March-June) and relative to girls born just after the cut-off. Parents (and, perhaps, school teachers) appear to be overly

\footnotetext{
${ }^{10}$ Table 2 below examines the sensitivity of the results to the specification of the control function.
} 
Figure 3. School starting age and birth month

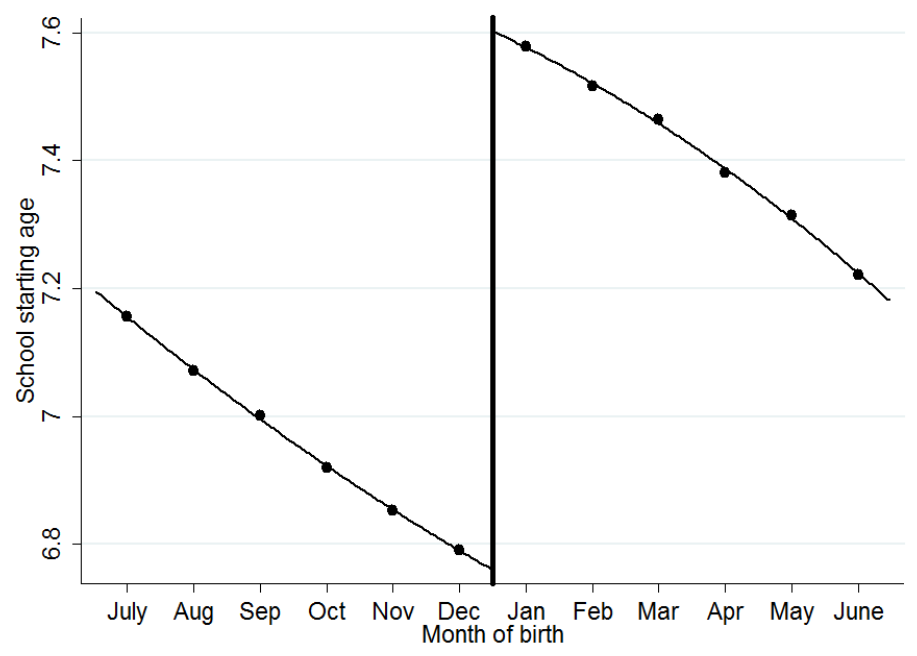

Notes: The figure is based on individuals born 1948 who are included in the ETF-data (those born on the 5th, 15th, and 15th each month). Discontinuity at threshold: 0.86 (standard error: 0.02). Regression lines are 2nd order polynomials fitted separately to the individual data on each side of the cut-off. The solid vertical line depicts the school entry cut-off. Those just to the left of the threshold are born in December 1948 and those just to the right of the threshold are born in January 1948. In constructing this figure we have assumed that there is no underlying trend in SSA.

optimistic about the school performance of boys born just after the cut-off.

This reasoning suggest that we would ideally like to allow for differential effects of starting early and late. Unfortunately, we cannot do this since we only have one cut-off. Our instrumental variables results thus reflect the combined effect of starting early or late.

\section{Descriptive analysis}

We illustrate the gist of our results by a set of graphs. In these graphs we relate the outcomes to the school entry law and month of birth. Figure 5 presents the aggregate picture by showing how education and earnings at various ages are related to month of birth. The top-left graph pertains to years of schooling; the top-right graph to earnings at age 18; the bottom-left graph to earnings at age 35; and the bottom-right graph to earnings at age 62 . We measure agespecific earnings relative to average prime-age earnings (age 25-54) per cohort. Notice that this is just a normalization to facilitate interpretation.

Figure 5 shows that individuals born just after the school-entry cut-off have (significantly) higher educational attainment. The jump at the cut-off amounts to an increase in years of 
Figure 4. Early and late school starts by birth month and gender
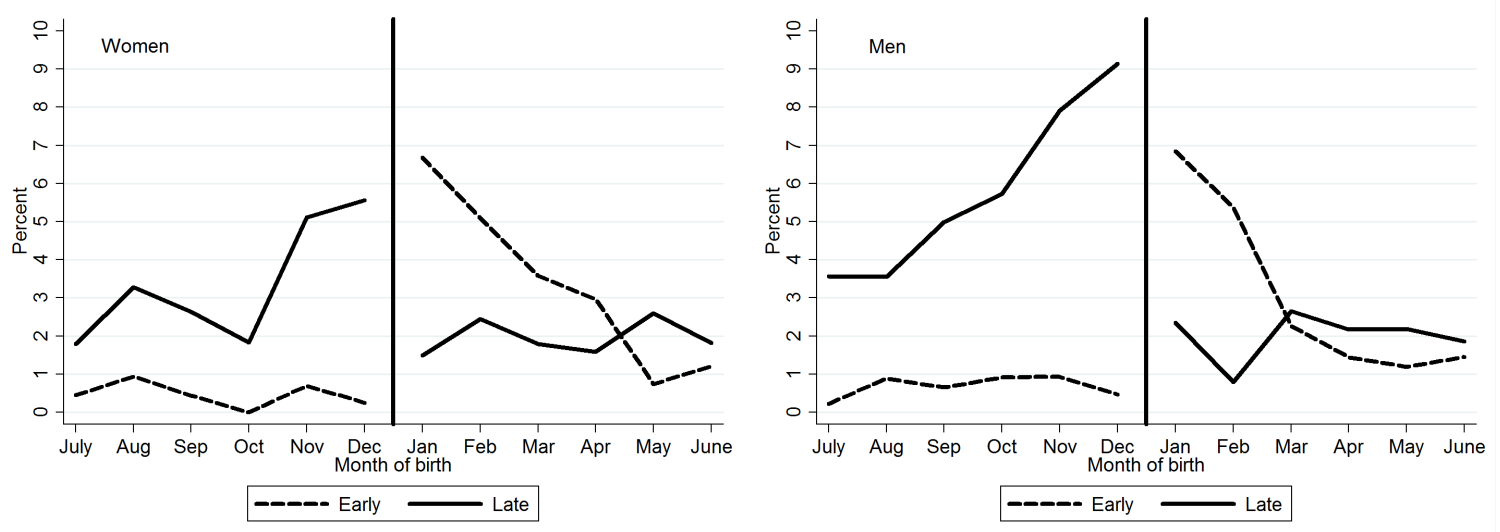

Notes: The graphs are based on individuals born 1948 who are included in the ETF-data (those born on the 5th, 15th, and 15th each month). The solid vertical lines depict the school entry cut-off. Those just to the left of this threshold are born in December 1948; those just to the right of the threshold are born in January 1948.

schooling of 0.14 years.

Remaining three figures show earnings effects at various stages of the life-cycle. The topright graph illustrates that individuals born just after the cut-off have lower earnings at age 18. Individuals born just after the cut-off enter the labor market almost a full year later and have more education. Both of these factors imply less experience for given age, which contributes to lower earnings early on in the career. Earnings at age 35, on the other hand, is unrelated to the expected school starting age; see the bottom-left graph. The earnings premium associated with the increase in education seems to be balanced by the loss of experience associated with starting school at an older age. The bottom-right graph shows that earnings close to retirement is higher for those born just after the cut-off; the increase amounts to $4 \%$ of average prime-age earnings.

Hidden in the averages shown in Figure 5 there is substantial heterogeneity. Figure 6 and Figure 7 examine heterogeneous effects on education and prime-age earnings respectively.

Figure 6 shows the relationship between educational attainment and month of birth for various groups. The top panel presents this relationship separately by gender. Being born just after the cut-off has a bigger effect on education for women than for men: the jump at the cut-off corresponds to 0.16 years of schooling for females and 0.11 years for males. Males born in January and February do not gain as much by being born after the cut-off as their female counterparts. We think the explanation for this fact lies in the behavior illustrated in Figure 4 where it seems that parents are overly optimistic about the school performance of boys born in January and February. To the extent that parents err in their judgment, boys 


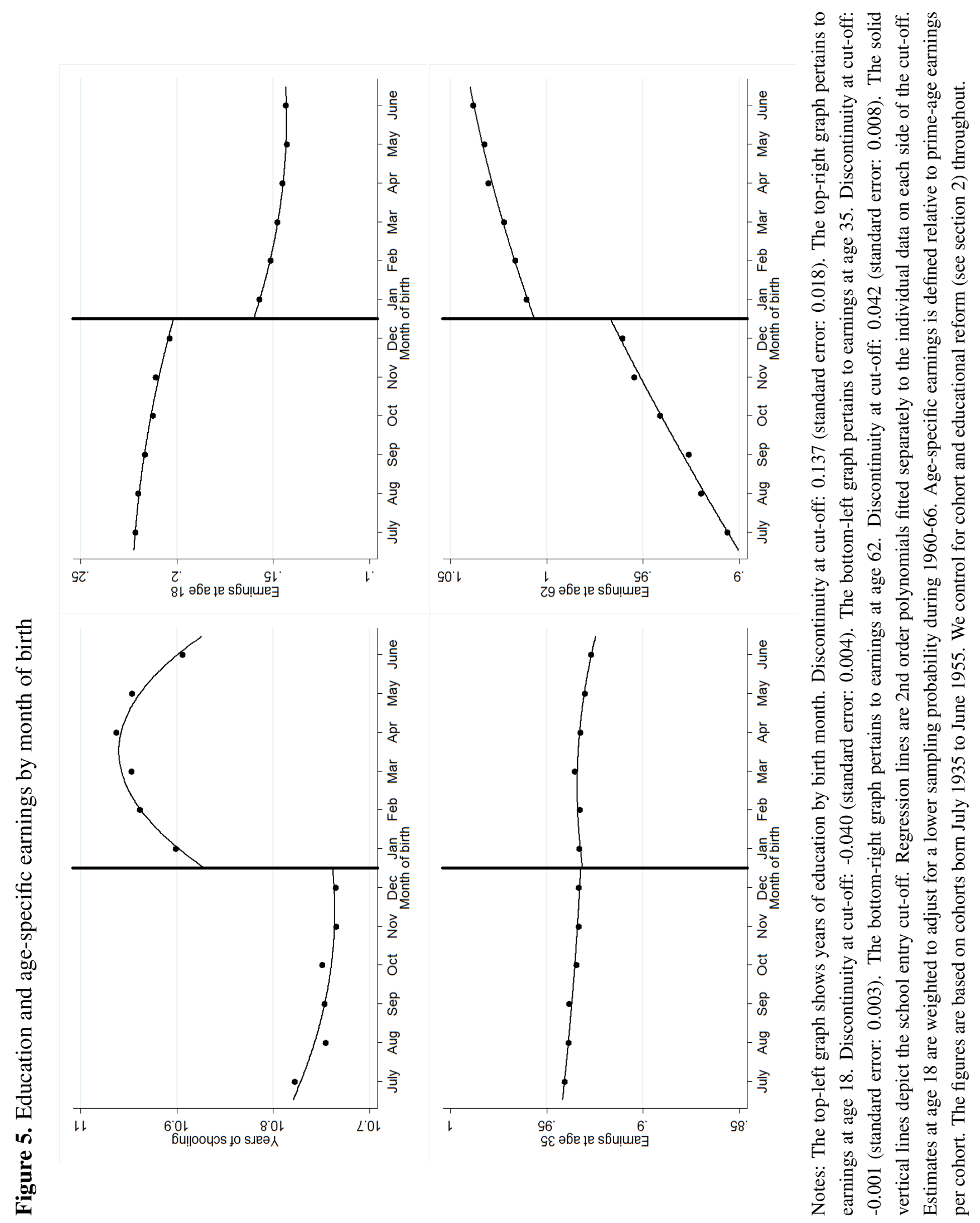


who start early are particularly hurt by being the youngest in class. The manifestation of this is that January and February born men have lower attainment than we would expect, both relative to females and relative to men born March to June.

The lower panel presents the relationship between years of schooling and month of birth by the education of their parents. Individuals born to low-educated parents (both parents have at most 7 years of education) and just after the cut-off have an additional 0.18 years of education relative to those born just before the cut-off. For individuals with high-educated parents (at least one parent have more than 7 years of education), the jump at the cut-off corresponds to 0.12 years of schooling. Again, there seems to be something particular going on among individuals born in January and February to high-educated parents. We think the likely explanation is the same as for the gender difference. The probability of starting late is roughly the same for children born in December across family background $(8.3 \%$ for individuals with low-educated parents; $7.0 \%$ for individuals with high-educated parents). However, the probability of starting early for individuals born in January to high-educated parents is substantially higher $(7.6 \%)$ than among individuals born in January to low-educated parents $(4.6 \%)$. It seems that highly educated parents tend to overestimate the performance of their January and February born children, which may have negative consequences for their educational outcomes.

Figure 5 showed that school starting age mainly affects the allocation of life-time labor supply for the average worker: on average, earnings during prime-age is unaffected by the school entry cut-off. Again, there is substantial heterogeneity hidden in the average; see Figure 7. And, qualitatively, the difference across groups line-up well with the differential impact on education across groups.

The top-left graph shows that women who are born just after the school entry cut-off have higher earnings at age 35 . The effect amounts to $1.1 \%$ of prime-age earnings (with a standard error of $0.4 \%$ ). The top-right graph shows the corresponding relationship for men. For men, being born after the school entry cut-off implies a loss of $0.6 \%$ (standard error $0.3 \%$ ). For individuals with low-educated parents, the effect of being born just after the school entry cut-off is positive and amounting to $1.0 \%$ (standard error $0.5 \%$ ), while there is no effect for individuals with high-educated parents (the estimate is $-0.4 \%$ with a standard error of 0.3 ).

For men and those with high-educated parents, the underlying relationship between birth month and outcomes to the right of the discontinuity suggests that the impact on education is key to understand the effect on earnings at age 35. The downward jump at the discontinuity for men, in particular, is accounted for by a loss of a year of potential experience for those born just after the cut-off. In general, a year of experience has a bigger effect on the earnings 


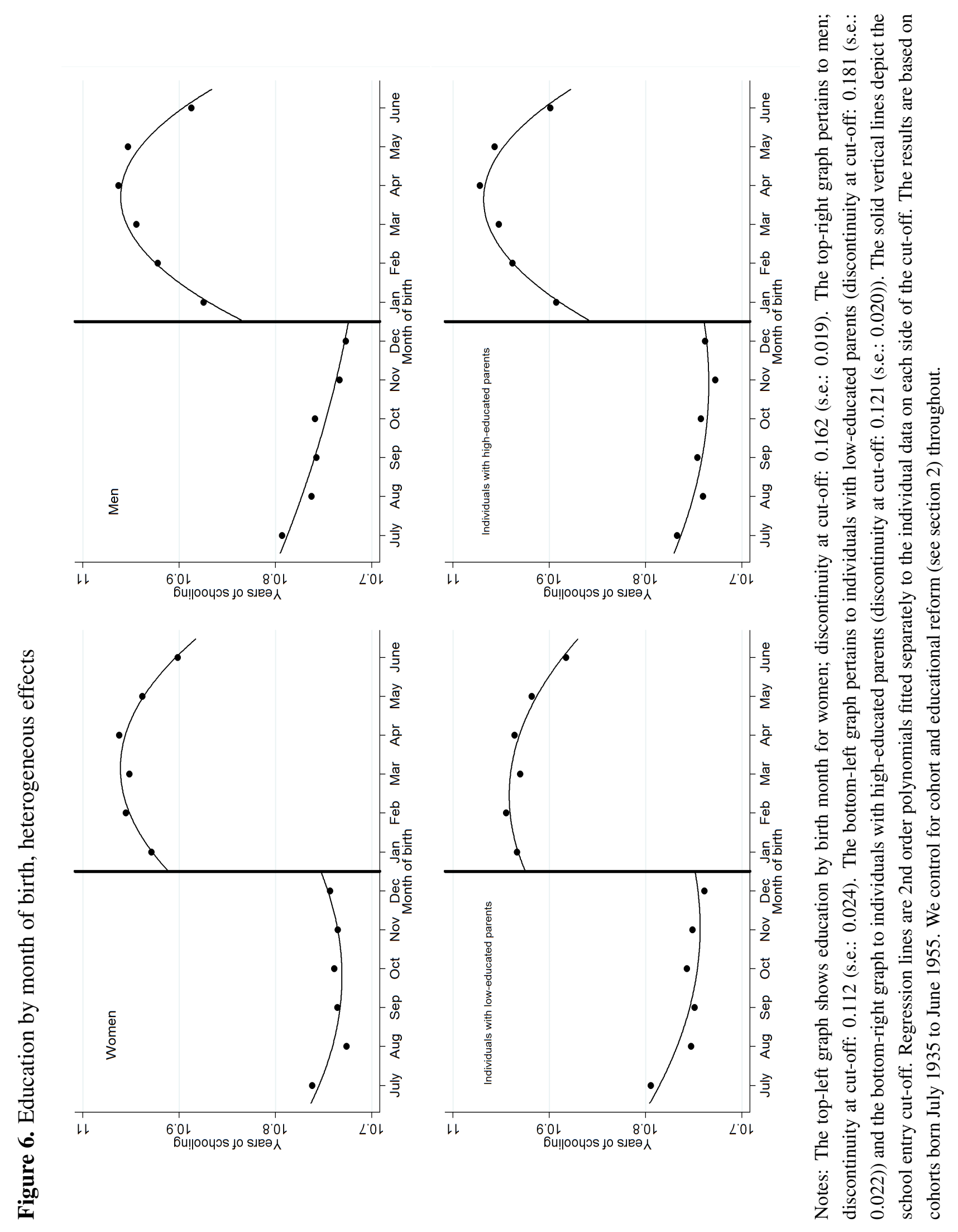




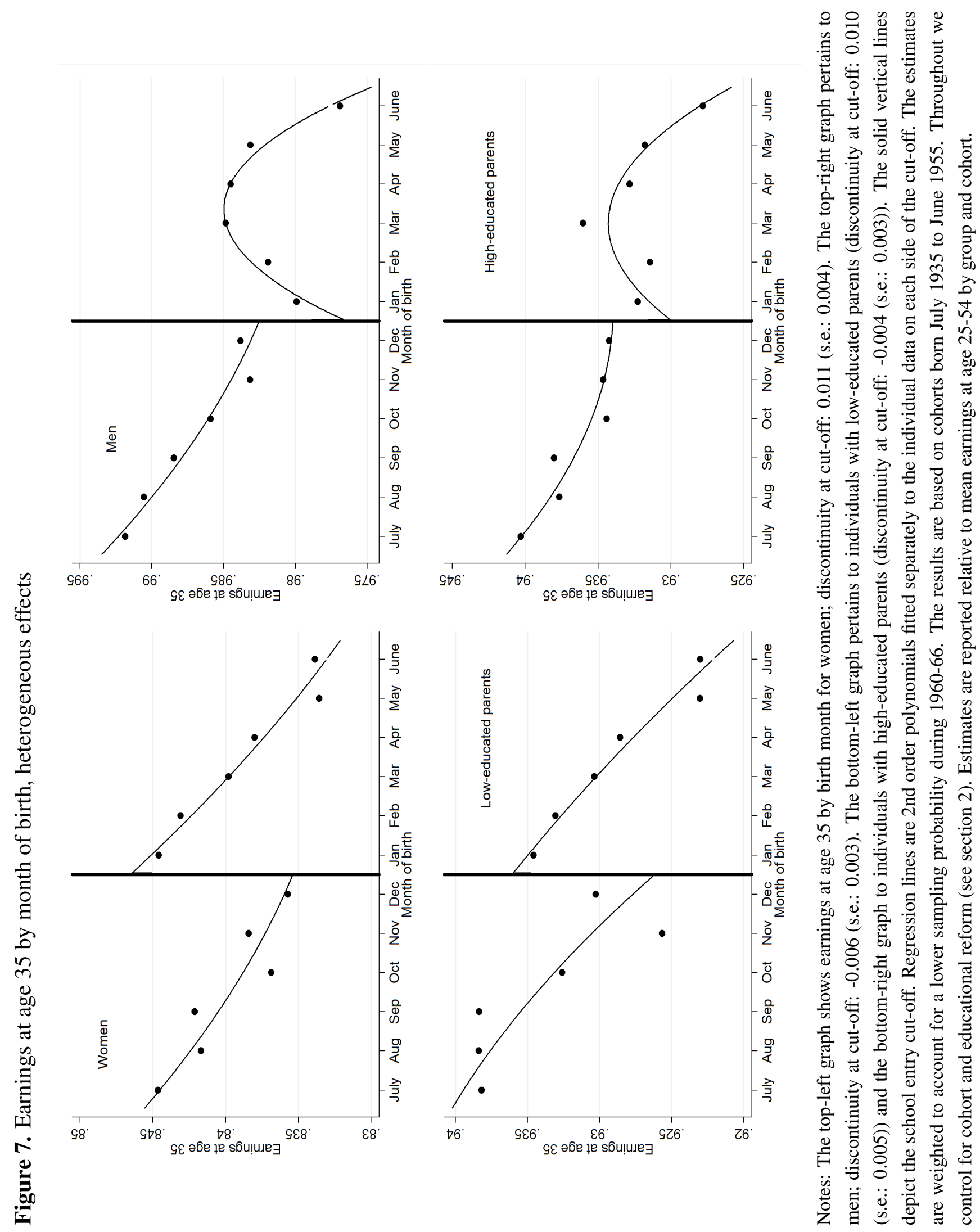


of men than on the earnings of women.

In Section 8 we probe deeper into the earnings results, by, inter alia, investigating whether the positive effects for women and those with low-educated parents are due to improved employment prospects or wage increases.

\section{The effect of SSA on educational attainment}

This section presents a collection of evidence on the importance of age at school start for schooling. Section 7.1 contains specification analyses; Section 7.2 reports results by gender, parental education, and cohort; Section 7.3 examines whether the comprehensive school reform reduced the importance of initial advantage by postponing tracking.

\subsection{Specification analysis}

Here we present reduced form evidence on the importance of month of birth for educational attainment. The main question is how flexibly we need to control for the underlying relationship between birth month and education in order to obtain reliable estimates. Table 2 presents the results.

Column (1) shows the results of a baseline specification including a 2nd order polynomial in birth month (interacted with the cut-off): being born after the cut-off increases years of schooling by 0.137 years. ${ }^{11}$ Column (2) interact these controls with cohort; this only improves precision but has no effect on the point estimate. Columns (3) and (4) shows the results of altering the window width. ${ }^{12}$ Column (3) is based on individuals born November-February (i.e., \pm 2 from the cut-off). The estimate is slightly higher than in the baseline specification in column (1). Column (4) extends the window to include individuals born in October and March as well. The estimate is identical to the one shown in column (1). In column (5) we add baseline covariates (gender, parental education, and parental employment). According to Table 1 this addition should not affect the estimates and it does not. In column (6), we exclude the cohort and birth parish "cells" that were subjected to the two education reforms described in Section 2; this restriction has no implications for the estimates.

It is with the specification in column (1) that we proceed. Other conceivable specifications do not deliver appreciably different results.

\footnotetext{
${ }^{11}$ A specification with a third order polynomial, interacted with cut-off, delivers slightly higher reduced-form estimates. But given Figure 5 (see top-left) we see no reason to allow for such flexibility.

${ }^{12} \mathrm{~A}$ specification including only individuals born December-January does not pass a balancing test and therefore we do not show it.
} 
Table 2. Effects of being born after cut-off on education and SSA, specification analysis

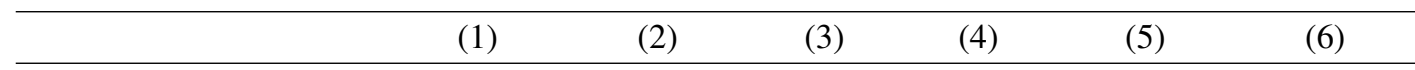

A. Dependent variable: Years of schooling (Reduced Form)

$\begin{array}{lcccccc}\text { After cut-off } & 0.137 * * & 0.138^{* *} & 0.151^{* *} & 0.135^{* *} & 0.138^{* *} & 0.131^{* *} \\ & (0.018) & (0.013) & (0.020) & (0.031) & (0.016) & (0.016)\end{array}$

B. Dependent variable: SSA (1st stage)

$\begin{array}{lcccccc}\text { After cut-off } & 0.858^{* *} & 0.858^{* * *} & 0.905^{* *} & 0.929^{* *} & 0.856^{* *} & 0.871^{* *} \\ & (0.018) & (0.018) & (0.028) & (0.038) & (0.020) & (0.025)\end{array}$

Month of birth controls

1 st order

2nd order

Interacted w. cutoff

Interacted w. cohort

Window width

With covariates

$\begin{array}{llllll}\sqrt{ } & \sqrt{ } & \sqrt{ } & & & \\ \sqrt{ } & \sqrt{ } & \sqrt{ } & \sqrt{ } & \sqrt{ } & \sqrt{ } \\ & \sqrt{ } & & & & \sqrt{ } \\ & & & & & \end{array}$

Without reform years

$\begin{array}{llllll} \pm 6 & \pm 6 & \pm 2 & \pm 3 & \pm 6 & \pm 6\end{array}$

\# individuals (RF)

$\begin{array}{cccccc}2,037,166 & 2,037,166 & 628,789 & 978,975 & 1,732,987 & 1,513,723 \\ 11,229 & 11,229 & 3,552 & 5,456 & 10,126 & 5,741\end{array}$

Notes: The regressions in panel A are based on individuals born July 1935 to June 1955 and include cohort fixed effects. The regressions in panel B are based on a 10\% sample born 1948. Throughout we control for educational reform (see section 2). For years of schooling, standard errors (shown in parentheses) allow for clustering on the discrete values of the assignment variable. For school starting age, standard errors are robust, since clustered standard errors are unreliable with few clusters (the robust standard errors are at least twice as large as the clustered ones); see Angrist and Pischke (2008). **/* = significant at the 5/10 percent level. 
Table 3. IV estimates of SSA on educational attainment

\begin{tabular}{lccccc}
\hline & All & \multicolumn{2}{c}{ By gender } & \multicolumn{2}{c}{ By parental ed } \\
\hline & & Females & Males & Low & High \\
\hline \multirow{3}{*}{ SSA } & $(1)$ & $(2)$ & $(3)$ & $(4)$ & $(5)$ \\
& $0.159^{* *}$ & $0.181^{* *}$ & $0.134^{* *}$ & $0.217^{* *}$ & $0.141^{* *}$ \\
& $(0.021)$ & $(0.021)$ & $(0.029)$ & $(0.027)$ & $(0.024)$ \\
\# individuals & $2,037,166$ & 993,443 & $1,043,723$ & 566,035 & $1,412,096$ \\
\hline
\end{tabular}

Notes: The regressions are based on individuals born July 1935 to June 1955. All regressions include cohort fixed effects and control for educational reform (see section 2), as well as a second order polynomial in birth month which is interacted with cut-off. After cutoff ( $=1$ if individuals are born January-June) is used to instrument SSA. Individuals with low-educated parents are defined as having mothers and fathers with at most 7 years of education. Standard errors, shown in parentheses, allow for clustering on the discrete values of the assignment variable and are corrected for the two-sample nature of our IV approach; see Inoue and Solon (2010). $* * / *=$ significant at the $5 / 10$ percent level.

\subsection{Main results}

Table 3 reports instrumental variables (IV) estimates of the effects of School Starting Age (SSA) on educational attainment.

Column (1) reproduces the baseline estimate implied by column (1) in Table 2 . The effect of starting school when you are one year older is to increase educational attainment by 0.159 years. This estimate can be compared to the OLS estimate using only the cohort born 1948. The OLS estimate is -0.329 (standard error: 0.073) and thus severely downward biased. ${ }^{13}$

Column (2) and (3) present separate estimates by gender. Females are affected to a greater extent than males. Columns (4) and (5) produce separate estimates by parental education. Those with low-educated parents are affected by SSA to a greater extent that those with high-educated parents.

How do these results compare to those in the previous literature? The most obvious point of comparison is the paper by Black et al. (2011) which is based on data for Norway. They study cohorts born 1962-70 and find no effects on educational attainment on average and that years of schooling increases by 0.038 years among women. Their estimates are an order of magnitude lower than the ones we present in Table 3. We think a contributing reason is that they study cohorts observed after the Norwegian version of the comprehensive school reform. The Norwegian reform was modeled after the Swedish one, but was implemented a few years

\footnotetext{
${ }^{13}$ We exclude the control function in month of birth to identify SSA in the OLS regression.
} 
after the Swedish reform. In the next section we present evidence that the comprehensive school reform reduced the importance of SSA.

Another point of comparison is Dobkin and Ferreira (2010). They find that individuals born before the cut-off have more education, a result that runs opposite to the evidence presented in Table 3. But this result should not be interpreted as the effect of school starting age. The U.S. compulsory schooling laws imply that older school starters have fewer years of compulsory schooling (see Angrist and Krueger 1991). Therefore, the results in Dobkin and Ferreira (2010) reflect the combined effect of school entry and school leaving age legislation.

There are a few other papers available in the literature which document results that are more in line with ours. Plug (2001) and Fertig and Kluve (2005) both find that SSA has a positive effect on educational attainment.

\subsection{Does the selectivity of the school system affect the importance of SSA?}

The comprehensive school reform started with the cohort born 1942 and was implemented gradually across the country. The dashed line in Figure 8 shows the share of each cohort that was born in parishes unaffected by the reform. To begin with, the reform was rolled-out rather slowly. But after the slow start, there was a fairly rapid expansion. By the cohort born $1955,98 \%$ of the cohort grew up in a parish that had implemented the reform.

Along with the expansion of the reform, Figure 8 presents separate estimates for the birth cohorts that were potentially affected by the reform; see the solid line. There is a substantial decline in the SSA effect starting with the cohorts born in the late 1940s. From then on, the SSA effect declines along with the rapid expansion of the comprehensive school reform. It is tempting to conjecture that the decline is due to the comprehensive school reform.

The purpose of this subsection is to add more substance to this conjecture. We proceed as follows. First, we estimate our main equation separately by reform regime, i.e.,

$$
y_{i c p}^{R}=\lambda_{R} S S A_{i c p}+b_{R}^{k}\left(M_{i c p}\right)+\theta_{c}^{R}+\theta_{p}^{R}+\mu_{i c p}^{R}
$$

where $c$ denotes cohort, $p$ parish, $R=0,1$ indicates whether a particular parish has reformed or not, and $b^{k}(\cdot)$ a kth order polynomial in birth month. Let $R_{i c p}=0,1$ indicate whether an individual was born in a parish that implemented the reform for cohort $c$. The pooled regression corresponding to equation (5) is

$$
y_{i c p}=\kappa\left[R_{i c p} \times S S A_{i c p}\right]+\lambda_{0} S S A_{i c p}+b_{0}^{k}\left(M_{i c p}\right)+b_{1}^{k}\left(M_{i c p}\right)+\theta_{c R}+\theta_{p R}+\mu_{i c p}
$$


Figure 8. The comprehensive school reform and the impact of SSA on education by cohort

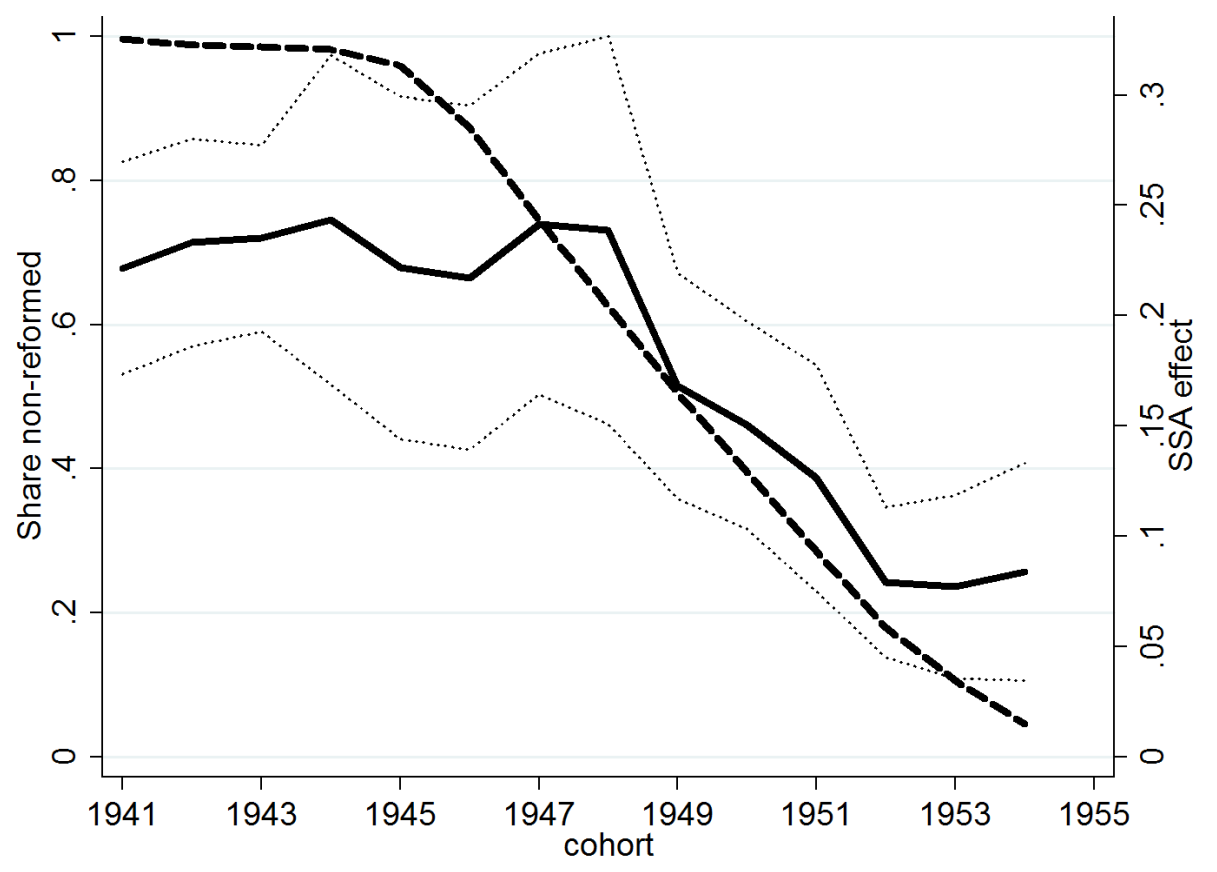

Notes: The figure is based on individuals born July 1939 to June 1955. The SSA effects are estimated separately by cohort \pm 2 cohorts. The specification includes a 2 nd order polynomial in birth cohort interacted with the cut-off and controls for educational reform (see section 2). The solid line shows IV-estimates and the dotted lines depict $90 \%$ confidence bands (which are based on clustered and corrected standard errors). The dashed line presents the share of each cohort that were born in non-reformed parishes. 
where $\theta_{c R}$ denotes fixed effects that allow the cohort effects to vary by reform and $\theta_{p R}$ do the same thing for the parish fixed effects. Notice that the main effect of the reform is swamped by these fixed effects. In equation (6), $\kappa$ is the coefficient of interest.

An advantage of pooling the regressions is that we can be more flexible in specifying the relationship between birth month and years of schooling than in equation (6). In particular we can introduce fixed effects for the interaction between cohort and being born after the cut-off as well as fixed effects for cohort by parish. The cohort by parish fixed effects take care of any trends in educational attainment that vary across parishes (and the main effect of the reform). The cohort by cut-off fixed effects take care of any changes in the relationship between education and birth month over cohorts (and the main effect of being born after the cut-off). With the inclusion of these fixed effects, the main effects of the reform and SSA are not identified, but the coefficient of the interaction term, $\kappa$, still is.

Notice that the reform indicator varies by calendar year while our definition of a cohort is from July to June. To ensure that this does not have a mechanical effect on the relationship between being born after the school entry cut-off and educational attainment, we exclude the reform year. ${ }^{14}$ Moreover, since there is some uncertainty in the timing of the reform we also exclude the year preceding and following the reform. Notice, finally, that we assign individuals to reform status on the basis of parish of birth. ${ }^{15}$

Table 4 shows the results. Since the reform started with individuals born 1942, we exclude individuals born prior to this year. We also exclude individuals who were born in parishes that introduced the reform after 1953 since these do not contribute to identification (given that we exclude the reform year and the preceding year). ${ }^{16}$

The first two columns show estimates by reform regime. The reform implies that school entry age has a smaller impact on educational attainment as conjectured above. Column (3) shows that the difference between the two estimates is statistically significant and that the drop in educational attainment amounts to 0.099 years. Column (4) shows the most elaborate specification which includes fixed effects for cohort by birth month and cohort by parish. Again, SSA has a lower effect on educational attainment in reformed parishes: the estimate on the interaction term is -0.098 , with a standard error of 0.046 .

\footnotetext{
${ }^{14}$ For a reform year, individuals born after the cut-off, who start school at the normal time, automatically get extra schooling relative to those born just before the cut-off.

${ }^{15}$ The Appendix describes how we assign reform status to individuals.

${ }^{16}$ We could of course include individuals born prior to 1942 in the comparison group. We prefer the current approach since, a priori, we think the "common trends" assumption is more palatable with fewer years of prereform data. Nevertheless, our conclusions do not depend on the sample restriction. With all birth cohorts, the estimate on the interaction term is -0.107 (standard error: 0.037) in a specification corresponding to column (4) in Table 4.
} 


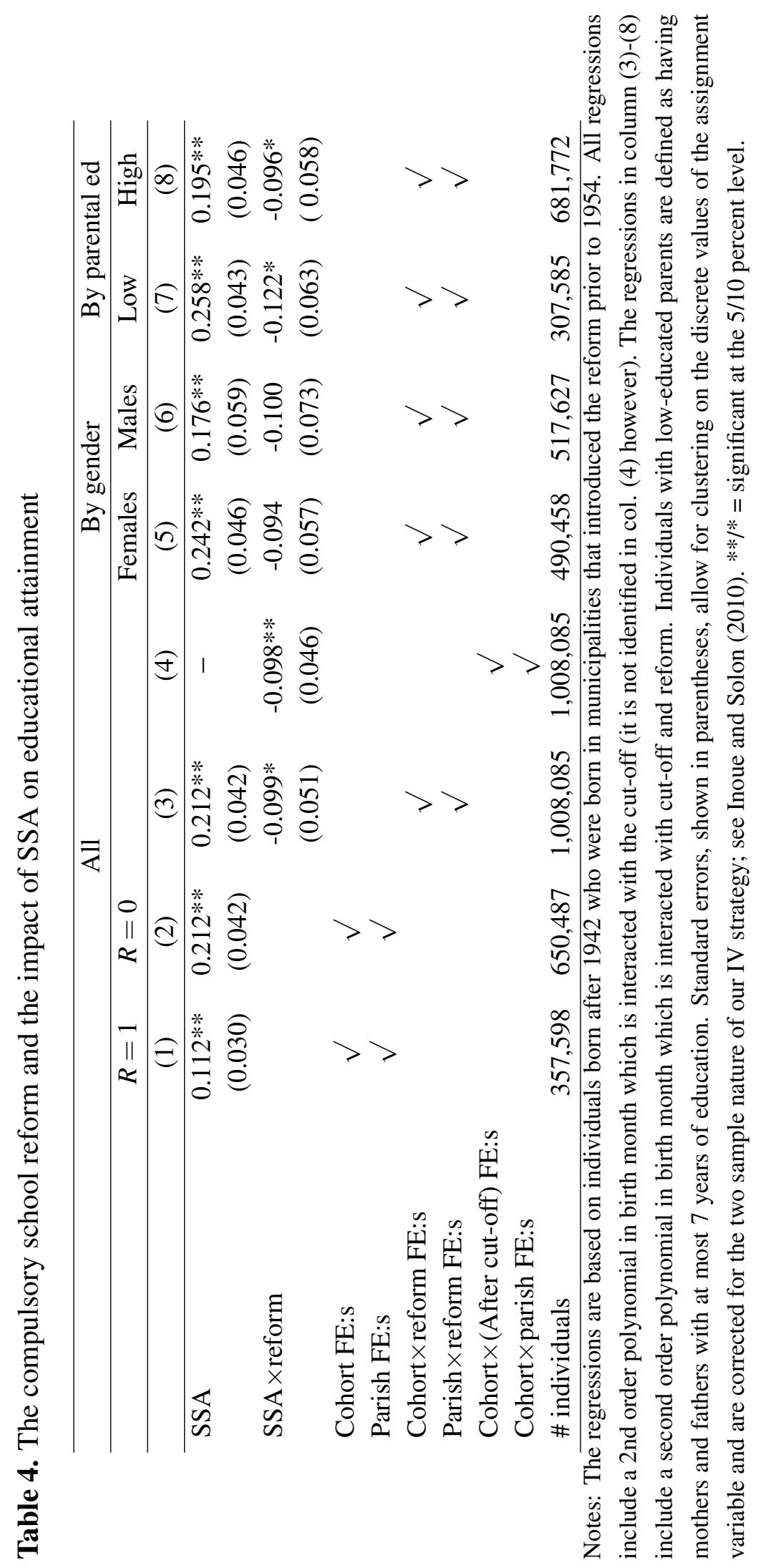


Since the specifications in columns (3) and (4) yield identical results, we proceed with the simpler specification in column (3). Columns (5)-(8) present separate estimates by gender and parental education. The comprehensive school reform did not affect the relationship between SSA and educational attainment differently across groups.

The estimates shown in Table 4 have reduced-form interpretations, since exposure to the reform depends on the parish of residence at the time when the reform was implemented. To the extent that individuals change reform status by moving parish, our estimates are lower bounds on the true treatment effects. Unfortunately we do not have the data do assign a parish of residence to all individuals at age 10 (or age 13). However, the evidence reported in Meghir and Palme (2005) suggests that the problem is minor. They find that only $9.9 \%$ changed reform status by moving. Estimates of the treatment effects can thus be obtained by dividing the reduced form estimates by 0.901 (the fraction that did not change reform status). Interpreted literally, this means that the reform reduced the impact of school starting age on educational attainment by 0.11 years.

Table 4 shows that initial differences, caused by variation in school starting age, are more likely to persist in school systems where students are tracked early on. We view this evidence as substantially more credible than the evidence reported Bedard and Dhuey (2006) who compared age effects across countries while children are still in school.

\section{The effect of SSA on life-time earnings, employment, and wages}

The variation in school starting age affects many margins influencing the final earnings outcome. Most obviously, it has an effect on educational attainment. Perhaps as obviously, children who start school one year later enter the labor market one year later, conditional on age and schooling (and thus have less experience throughout the career). In addition, experience is lower because late school starters have more schooling. Finally, their may be other achievement differences by age at school start conditional on years of compulsory schooling.

This section documents the effects of school starting age on life-time earnings, wages, and employment. Section 8.1 illustrates the effects on the age-earnings profiles. Section 8.2 considers the effects on earnings, employment and wages during prime-age. Section 8.3, finally, examines whether the present value of earnings is affected by SSA. Throughout, we focus on the total effect of school starting age on earnings (without controlling for experience and schooling). This parameter captures individual benefits and costs of alternative school starting ages. 


\subsection{Effects of school starting age on the age-earnings profile}

We present the broad picture in Figure 9. The evidence shown in the figure comes from estimating equation (1) separately by age using instrumental variables. Earnings at each age includes zero-earners and is measured relative to (cohort- and group-specific) mean earnings during prime-age (age 25-54). The top-left graph shows the effects of SSA on the ageearnings profile, averaged over all individuals. The top-right graph pertains to individuals with low-educated parents; the bottom-left graph to women; and the bottom-right graph to men. ${ }^{17}$

Overall, the results are very much in line with the results in Figures 5 and 7. The topleft graph shows the effects of school starting age on the age-earnings profile. On average, there are initial earnings losses due to later labor market entry and consequent loss of experience. But after age 55, until the nominal retirement age, school starting age has positive and substantial effects on earnings. ${ }^{18}$

The positive effects after age 55 are driven by positive employment responses towards the end of working life. In other words, school starting age delays retirement. Notice that eligibility for old-age retirement is determined by your birthday. Individuals become eligible when they turn 61. The normal retirement age, prior to the pension reform in the late 1990s, was the 65th birthday. After the pension reform, the statutory retirement age is 67 . The focal point in retirement behavior is thus the birthday. ${ }^{19}$

On average, SSA only affects the allocation of labor supply over the life-cycle; there are no effects during prime-age. ${ }^{20}$ However, the top-right graph shows that the SSA effects are decidedly more positive for those with low-educated parents than for the remainder of the population. Similarly, the bottom panel illustrates that the effects tend to be more positive for women than for men. ${ }^{21}$ As noted earlier, it is for women and individuals with loweducated parents that we find the most positive effect on educational attainment (see Table 3).

\footnotetext{
${ }^{17}$ Since individuals with high-educated parents comprise almost three quarters of the sample, the overall shape of the graph for this (omitted) group is similar to the graph for all individuals.

${ }^{18}$ The exact magnitude of the initial losses and later gains should be interpreted with some care, since we do not observe all cohorts at all ages. While all cohorts are observed in the age interval 25-55, we primarily observe the younger cohorts in the lower age-range and the older cohorts in the upper age-range. Since the SSA effects on education varies over cohorts, the exact magnitudes at the lower and upper ends of the age-interval should be interpreted somewhat carefully. Having said this, we also note that the qualitative nature of the results remains for all cohort.

${ }^{19}$ According to data from LINDA (see Edin and Fredriksson 2000), 75\% of individuals born 1915-34 retired on their birthday.

${ }^{20}$ Below we show that, on average, there are no wage effects of SSA during prime-age.

${ }^{21}$ The erratic pattern around age 20 for men has to do with military service. Older male school starters enter the military at an older age. Therefore earnings rebound and then drop around age 20.
} 


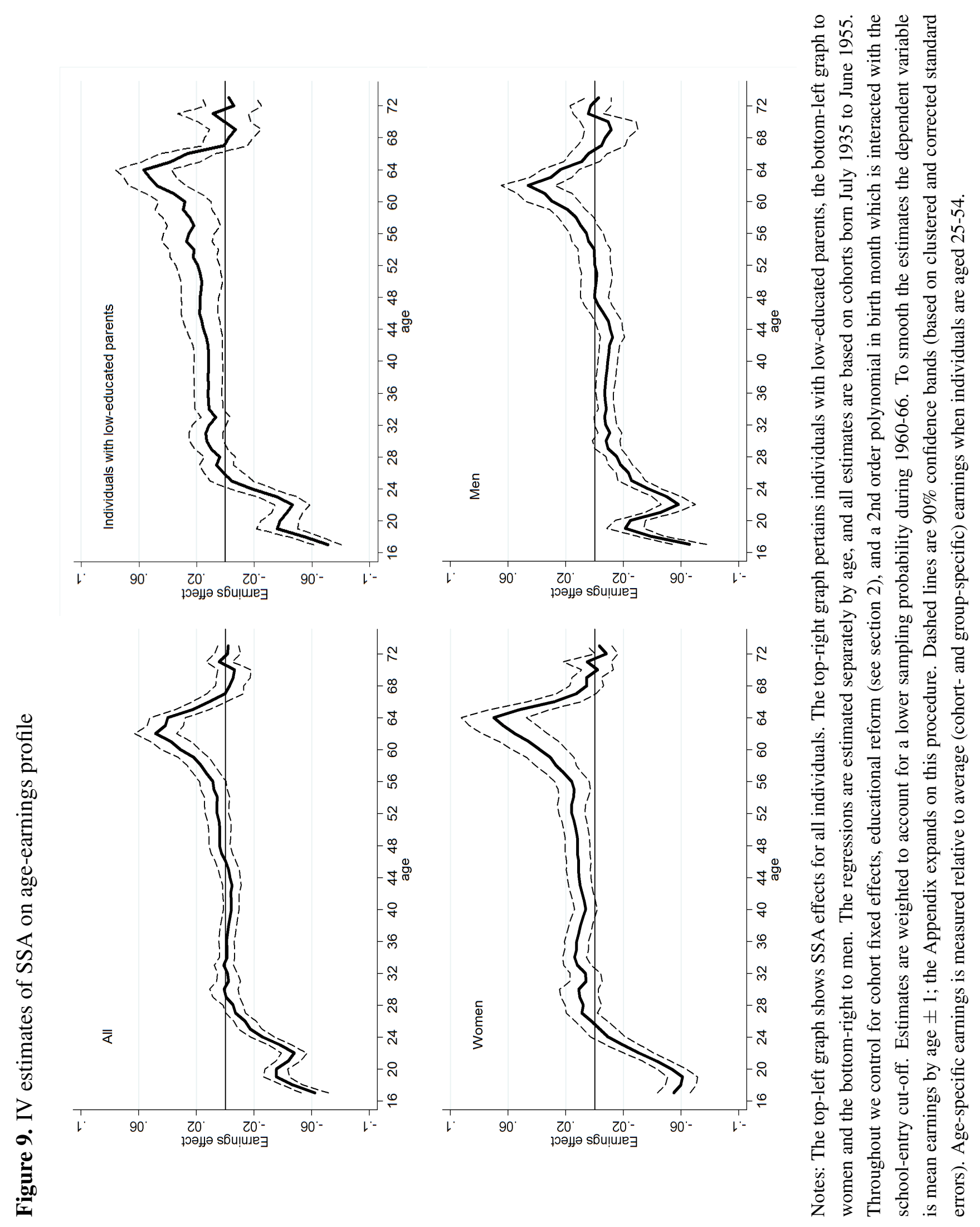


Individuals with low-educated parents and women are also most likely to be on the extensive employment margin.

In comparison to Black et al. (2011) the SSA effects shown in Figure 9 are more substantive. Black et al. (2011) follow individuals when they are aged 24-35. They find initial earnings losses, but by age 30 they have disappeared for both men and women. ${ }^{22}$ They also do a back-of-the envelope calculation assuming that there are no effects beyond age 35 . They conclude from this exercise that the effects on the present value of life-time earnings is negative. Judging from Figure 9 it is questionable whether this assumption is valid. Overall, we see no effect at age 35; yet, we observe positive effects of SSA from age 55 until retirement. We return to the effect of SSA on the present value of life-time earnings in Section 8.3.

\subsection{Effects of school starting age on earnings, employment and wages during prime-age}

This section probes deeper into the effects of school starting age during prime-age. In particular, we examine whether the earnings effects are due to employment or wage responses to school starting age.

Table 5 reports the results. The different rows display results for various outcomes. The different columns present results for all (column (1)), as well as by gender (columns (2) and (3)) and by parental education (columns (4) and (5)). Earnings estimates are reported relative to mean earnings. All estimates are multiplied by 100 to improve readability. Earnings and employment outcomes are thus reported in terms of percentage points and log wage outcomes in terms of percent.

The first row shows the results for earnings when individuals are prime-aged (25-54). We include years when individuals have no earnings; the estimates are thus not plagued by selection bias and potentially capture both labor supply and wage responses to variations in school entry age. The second row shows the effects on average employment during primeage. The remaining two rows show the employment and wage effects when individuals are aged 41-45. We focus on these particular ages since they are in the midst of prime age and since we lack information on wages prior to 1985 . The employment effects are reported in order to assess whether the wage estimates are plagued by selection bias. If there are significant effects on the probability of being full-time employed, the wage effects should be interpreted with some care.

\footnotetext{
${ }^{22}$ It is a bit surprising that the effects in Black et al. (2011) have disappeared by age 30. Figure A1 in the Appendix shows the age premium for men on the Swedish labor market. The wage loss associated with a loss of experience by 1 year is around $2 \%$ when individuals are age 32 .
} 
Table 5. IV estimates of SSA on earnings, employment, and wages

\begin{tabular}{lcccccc}
\hline $\begin{array}{l}\text { Outcome } \\
\text { (units) }\end{array}$ & & All & \multicolumn{2}{c}{ By gender } & \multicolumn{2}{c}{ By parental ed. } \\
& Age & $(1)$ & $(2)$ & $(3)$ & $(4)$ & $(5)$ \\
\hline & & & & & & \\
& $25-54$ & -0.212 & $0.992^{* *}$ & $-0.891^{* *}$ & $1.205^{* *}$ & $-0.719^{*}$ \\
$\begin{array}{l}\text { Earnings } \\
\text { (ppt.) }\end{array}$ & & $(0.327)$ & $(0.435)$ & $(0.386)$ & $(0.577)$ & $(0.374)$ \\
& & & & & & \\
$\begin{array}{l}\text { Employment } \\
\text { (ppt.) }\end{array}$ & $25-54$ & $0.330^{* *}$ & $0.677^{* *}$ & -0.039 & $0.696^{* *}$ & 0.232 \\
& & $(0.122)$ & $(0.178)$ & $(0.143)$ & $(0.217)$ & $(0.148)$ \\
$\begin{array}{l}\text { Full-time employment } \\
\text { (ppt.) }\end{array}$ & $41-45$ & 0.273 & $0.733^{* *}$ & -0.127 & $0.715^{* *}$ & 0.110 \\
& & $(0.190)$ & $(0.274)$ & $(0.182)$ & $(0.351)$ & $(0.230)$ \\
$\begin{array}{l}\text { ln(wage) } \\
\text { (percent) }\end{array}$ & $41-45$ & -0.274 & 0.137 & $-0.810^{* *}$ & 0.052 & -0.467 \\
\hline
\end{tabular}

Notes: To improve readability coefficients and standard error are multiplied by 100 . The regressions are based on individual panel data over the indicated age intervals. The effects of SSA are restricted to be the same across ages and thus have the interpretation as the average effects over the indicated age intervals. The regressions include individuals born July 1935 to June 1955. Earnings effects are defined relative to the cohort- and groupspecific mean. Employment is coded one if annual earnings exceed average earnings for individuals with wages below the 5th percentile. Full-time employment is coded one if annual earnings exceeds minimum full-time earnings. These earnings cut-offs are defined separately by gender, education, age, and time; see Appendix for more details. $\ln$ (wage) is the log of wages. After cutoff ( $=1$ if individuals are born January-June) is used to instrument SSA. All regressions include cohort fixed effect, a 2nd order polynomial interacted with the cut-off, and control for educational reform (see Section 2). Estimates are weighted to account for a lower sampling probability during 1960-66. Individuals with low-educated parents are defined as having mothers and fathers with at most 7 years of education. Standard errors, shown in parentheses, allow for clustering on the discrete values of the assignment variable and are corrected for the two-sample nature of our IV approach; see Inoue and Solon (2010). **/* = significant at the $5 / 10$ percent level. 
The first column shows that higher school starting age increases employment during prime-age by 0.3 percentage points on average. Nevertheless, there is no significant effect on earnings, presumably because forgone experience implies wage losses early on in the career.

Columns (2) and (3) show that the differential effects of SSA on educational attainment across gender spill over onto labor market outcomes. For women, we observe a positive effect on employment of 0.8 percentage points and no counteracting wage effect. For men, there is no effect on employment and a negative wage effect of 0.8 percent.

It is a bit surprising to see that the wage effects of starting school a year later persist when individuals are aged 41-45. The initial loss of experience seems to have very persistent effects. In fact, the negative wage impact for men does not disappear until individuals are aged 50. Figure A1 in the Appendix, which shows the age premium for men, corroborates this finding. The age premium for men is $1 \%$ when individuals are aged 43 ; it stays positive until individuals are 55 years-of-age. It is not until age 55 that the initial loss of experience is irrelevant.

A related question is whether the increase in educational attainment (in response to higher SSA) leaves a traceable impact on wages. In comparison to the U.S., returns to skills in Sweden are low. OLS estimates of the returns to education typically hover around 4 to 5 percent; see Leuven et al. (2004) for instance. When the increase in educational attainment is only relevant, this suggests a wage impact for men in the order of $0.5 \%$. At the returns to education typically found on the Swedish labor market, it will thus be hard to detect an effect of SSA on wages. In our view, it is more likely that the effects can be found along the extensive margin for groups that tend to be marginal.

Columns (4) and (5) present separate estimates with respect to parental education. Individuals whose parents are low-educated seem to gain from starting school at an older age, while the opposite is true for individuals with well-educated parents. Again, the differential effects on educational attainment map onto labor market outcomes; see Table 3. Moreover, the increase in education primarily leads to a response along the extensive margin for individuals with less educated parents. For this group of individuals, an increase in school starting age by 1 year raises average employment by 0.7 percentage points.

The overall message delivered by Table 5 is that school starting age has positive effects on the extensive margin for groups that tend to be marginal. For core workers, there is no employment response and sometimes a negative wage impact stemming from the initial loss of experience. Consistent with this, Figure 9 shows that we find positive effects close to retirement, i.e., at a point in the life-cycle where labor supply is highly elastic for all workers.

The regression results in Table 5 pools together all cohorts. Over cohorts (time), the 
female participation rate increased substantially. Table A1 shows that the employment rate of females aged 30-34 increased from 54\% in the cohorts born 1935-45 to $81 \%$ in the cohorts born 1945-55. This increase is most likely tied to a series of reforms implemented in the 1960s and 1970s. For instance, there was a move from household to individual taxation, child-care was built up, and a parental leave system was introduced. Females in the younger cohorts should arguably be considered core workers.

Now if females, to some extent, moved from being marginal to core workers and if school starting age primarily operates along the extensive employment margin, we should expect smaller effects of SSA on prime-age earnings over cohorts. Auxiliary regressions (not shown) suggest a decline in the effect of SSA on prime-age earnings for females over cohorts. We do not observe a corresponding decline for individuals with low-educated parents, a group that is likely to have been marginal throughout the time-period spanned by these data. This suggests that labor market attachment is also important for the effect of SSA on prime-age earnings.

\subsection{Effects of school starting age on present value of earnings}

The gains and losses of school starting age occur at various stages of the life-cycle (see Figure 9). The natural way of trading off initial losses with subsequent gains is to estimate the effect on the present value of earnings. This is the purpose of this section.

To conduct the analysis we must handle the fact that all cohorts are not observed throughout their careers. For the oldest cohorts, we miss the young ages and thus underrepresent the cost of entering school later; for the younger cohort, we miss the ages close to retirement and, therefore, the gains of starting later. We deal with this problem by placing additional weight on the cohorts observed during the ages that are missing for some cohorts.

The results from this exercise should be interpreted a bit carefully since Figure 8 shows that the effects of SSA vary somewhat across cohorts. Note, though, that we have also used only the cohorts that we we observe throughout the labor market career (those born July 1943 to June 1945) and do not get appreciably different results.

Table 6 reports the results. We take the entire earnings stream from age 18 to 64 into account and discount to present value at age 18. Across rows we present the results for alternative discount rates. The estimates are multiplied by 100 and reported relative to the present value of cohort-specific prime-age earnings.

The first row of Table 6 summarizes Figure 9. There is no effect on average. The positive effects for women and individuals with low-educated parents during prime-age are not 
Table 6. Effect of SSA on present value of earnings

\begin{tabular}{lccccc}
\hline & All & \multicolumn{2}{c}{ By gender } & \multicolumn{2}{c}{ By parental ed } \\
\hline Discount rate & $(1)$ & $(2)$ & $(3)$ & $(4)$ & $(5)$ \\
\hline \multirow{2}{*}{$r=0.00$} & -0.513 & 0.614 & $-1.197 * *$ & 0.720 & $-0.941^{* *}$ \\
& $(0.380)$ & $(0.535)$ & $(0.438)$ & $(0.647)$ & $(0.413)$ \\
$r=0.02$ & $-0.864 * *$ & 0.163 & $-1.480^{* *}$ & 0.219 & $-1.240 * *$ \\
& $(0.343)$ & $(0.496)$ & $(0.381)$ & $(0.586)$ & $(0.372)$ \\
& & & & & \\
$r=0.05$ & $-1.440 * *$ & -0.572 & $-1.955^{* *}$ & -0.610 & $-1.725 * *$ \\
& $(0.359)$ & $(0.525)$ & $(0.386)$ & $(0.600)$ & $(0.391)$
\end{tabular}

Notes: Estimates are multiplied by 100 to improve readability. The regressions are based on individuals born July 1935 to June 1955 . The present values are normalized by the cohort-specific discounted value of prime-age earnings. All regressions include cohort fixed effect, control for educational reform (see section 2), as well as a second order polynomial in birth month which is interacted with cut-off. After cutoff $(=1$ if individuals are born January-June) is used to instrument SSA. Estimates are weighted to account for a lower sampling probability during 1960-66. Moreover, we weight the data to account for the fact that some cohorts are not observed during all ages. Individuals with low-educated parents are defined as having mothers and fathers with at most 7 years of education. Standard errors, shown in parentheses, are clustered on the discrete values of the assignment variable and corrected for the two-sample nature of our IV approach; see Inoue and Solon (2010). **/* = significant at the $5 / 10$ percent level. 
sufficiently large to render the estimates statistically significant. For men and those with high-educated parents, there are (statistically) significant losses amounting to 1.2 and 0.9 percentage points respectively.

The second row shows the results when we discount the earnings stream at a realistic rate (2\%). The effect of SSA on discounted life-time earnings is $-0.9 \%$ of prime-age earnings for the average workers. With heavier discounting (5\%) we get uniformly lower estimates; see third row.

According to Table 6, there is no group where school entry age has a significant increase in discounted life-time earnings. Initial losses outweigh subsequent gains. With realistic discount rates, the loss amounts to 0.9 percent of discounted prime-age earnings for the average worker.

\section{Conclusion}

We study the long-run impact of school starting age among the cohorts born 1935-55. Higher school starting age implies an initial advantage which increases educational attainment in the long run. On average, an increase in school starting age by one year raises educational attainment by 0.16 years. The effects on educational attainment are more substantive than the effects found in a comparable study for Norway (see Black et al. 2011).

We show that the comprehensive school reform (which postponed tracking until age 16) reduced the effect of school starting age on educational attainment. Postponing tracking to an older age thus reduces the importance of having an initial advantage. This is the first paper that documents such effects in a convincing fashion.

A further value added of our study is that we trace the effects of entry age on prime-age earnings, employment, and wages for any given cohort. Overall, school starting age only affects the allocation of labor supply over the life-cycle. There are initial losses due to later entry into the labor market, but also later gains since those who start at an older age retire later. For individuals with low-educated parents, and to some extent women, we find increases in prime-age earnings in response to school starting age. Our favored interpretation is that the rise in educational attainment, caused by school starting age, primarily affects individuals who are likely to be on the extensive margin.

The impact of school entry age on employment and earnings around retirement implies

that studies which do not observe outcomes throughout the career are potentially misleading in terms of the life-time earnings impact. Despite higher earnings around retirement, however, there is no group where we find that school starting age causes statistically significant 
increases in discounted life-time earnings. On average, discounted life-time earnings fall by 0.9 percent (relative to discounted prime-age earnings) in response to later school start (at a discount rate of $2 \%$ ).

In summary, we think there are two general lessons from our analysis. First, our evidence shows that initial advantages are exacerbated by early tracking. Countries wishing to reduce the importance of initial advantage may consider postponing tracking. Second, any labor market effects of school starting age likely operate along the extensive employment margin and are, therefore, more important for marginal groups. In our view, it is unlikely that school starting age leaves traceable wage impacts for core groups on the labor market. 


\section{References}

Angrist, J.D. and Krueger, A.B. (1991). 'Does compulsory school attendance affect schooling and earnings?', Quarterly Journal of Economics, vol. 106, pp. 979-1014.

Angrist, J.D. and Krueger, A.B. (1992). 'The effect of age at school entry on educational attainment: An application of instrumental variables with moments from two samples', Journal of the American Statistical Association, vol. 87, pp. 328-336.

Angrist, J.D. and Pischke, J.S. (2008). Mostly Harmless Econometrics, Princeton University Press.

Bedard, K. and Dhuey, E. (2006). 'The persistence of early childhood maturity: International evidence of long-run age effects', Quarterly Journal of Economics, vol. 121, pp. 14371472.

Black, S.E., Devereux, P.J. and Salvanes, K.G. (2011). 'Too young to leave the nest? the effects of school starting age', Review of Economics and Statistics, vol. 93, pp. 455-467.

Datar, A. (2006). 'Does delaying kindergarten entrance give children a head start?', Economics of Education Review, vol. 25, pp. 43-62.

Dobkin, C. and Ferreira, F. (2010). 'Do school entry laws affect educational attainment and labor market outcomes?', Economics of Education Review, vol. 29, pp. 40-54.

Edin, P.A. and Fredriksson, P. (2000). 'Linda - longitudinal individual data for sweden', Department of Economics, Uppsala University.

Elder, T.E. and Lubotsky, D.H. (2009). 'Kindergarten entrance age and children's achievement: Impacts of state policies, family background, and peers', Journal of Human Resources, vol. 44, pp. 641-683.

Fertig, M. and Kluve, J. (2005). 'The effect of age at school entry on educational attainment in germany', IZA.

Fredriksson, P. and Öckert, B. (2005). 'Is early learning really more productive? the effect of the school starting age on school and labor market performance', IZA.

Holmlund, H. (2007). 'A researchers guide to the swedish compulsory school reform', SOFI, Stockholm University. 
Härnquist, K. (2000). 'Evaluation through follow-up', in (C. Jansson, ed.), Seven Swedish Longitudinal Studies in the Behavioral Sciences, Forskningsrådsnämnden, Stockholm.

Inoue, A. and Solon, G. (2010). 'Two-sample instrumental variables estimators', Review of Economics and Statistics, vol. 92, pp. 557-561.

Lee, D.S. and Card, D. (2008). 'Regression discontinuity inference with specification error', Journal of Econometrics, vol. 142, pp. 655-674.

Leuven, E., Oosterbeek, H. and van Ophem, H. (2004). 'Explaining international differences in male wage inequality by differences in demand and supply of skill', Economic Journal, vol. 144, pp. 478-498.

McCrary, J. (2008). 'Manipulation of the running variable in the regression discontinuity design: A density test', Journal of Econometrics, vol. 142, pp. 698-714.

Meghir, C. and Palme, M. (2005). 'Educational reform, ability and parental background', American Economic Review, vol. 95, pp. 414-424.

Muhlenweg, A.M. and Puhani, P.A. (2010). 'The evolution of the school-entry age effect in a school tracking system', Journal of Human Resources, vol. 45(2), pp. 407-438.

Murphy, K.M. and Topel, R.H. (1985). 'Estimation and inference in two-step econometric models', Journal of Business and Economic Statistics, vol. 3, pp. 370-379.

Plug, E. (2001). 'Season of birth, schooling and earnings', Journal of Economic Psychology, vol. 22, pp. 641-660.

J. P. Shonkoff and D. A. Phillips, eds. (2000). From Neurons to Neighborhoods: The Science of Early Childhood Development, National Academy Press.

Stipek, D. (2002). 'At what age should children enter kindergarten? a question for policy makers and parents', Social Policy Report, vol. 16, pp. 3-16. 


\section{Appendix}

\section{Descriptive statistics}

Earnings and employment Table A1 reports descriptive statistics on earnings, full-time employment, and employment by cohort, gender, parental education, and age.

Age premium for men Figure A1 shows non-parametric estimates of the age-wage premium for men. The estimates are derived by comparing the log wages of two adjacent cohorts for each age while holding time constant. When individuals are 43 years-of-age, there is a one percent effect of age on wages. After 54 years-of-age, the age premium turns negative.

Figure A1: Age premium for men, 1935-55 cohorts
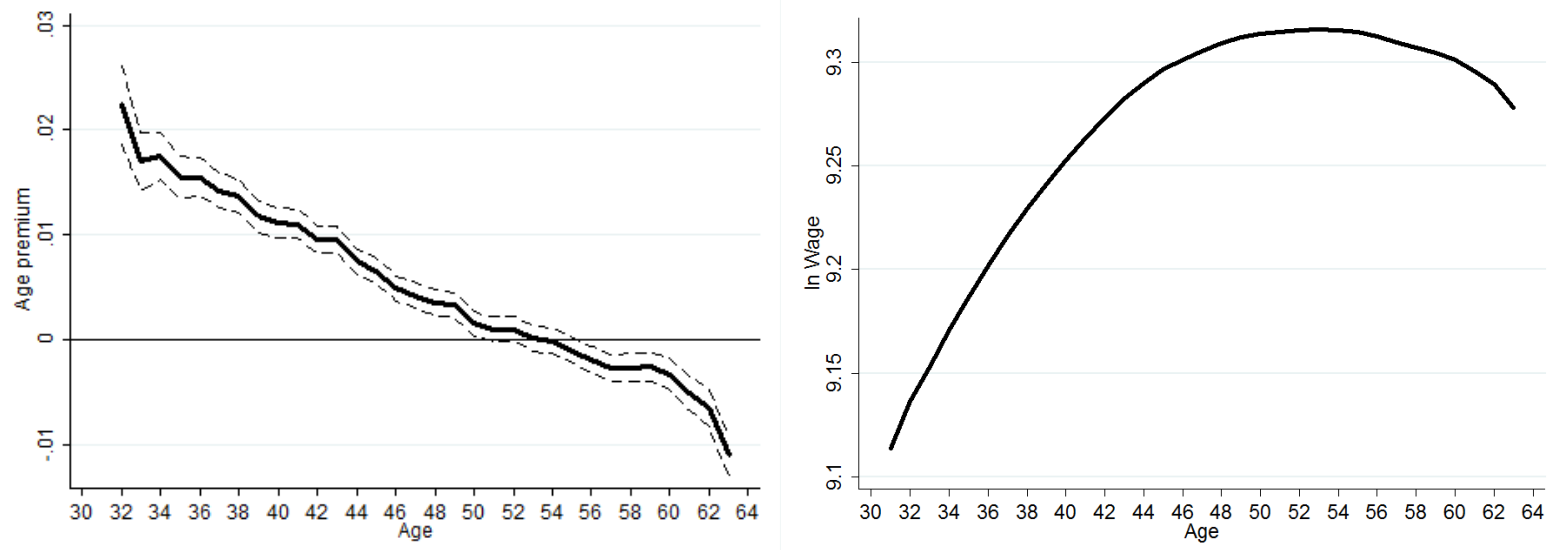

Notes: The graph on the left shows estimates of the age premium. The graph on the right cumulates these estimates using the mean log wage at age 31 as the starting point. The estimates are based on wage data available from 1985-2009, and the cohorts born July 1935 to June 1955 . Identification of the full age range is to some extent achieved by pooling cohorts. For someone born 1935 we observe wages from age 50 and onwards. For someone born 1955 we observe wages from age 30 to 54. Estimates are obtained by comparing to adjacent cohorts by age while holding time constant (time fixed effects). Dashed lines are $90 \%$ confidence bands (based on clustered standard errors). 


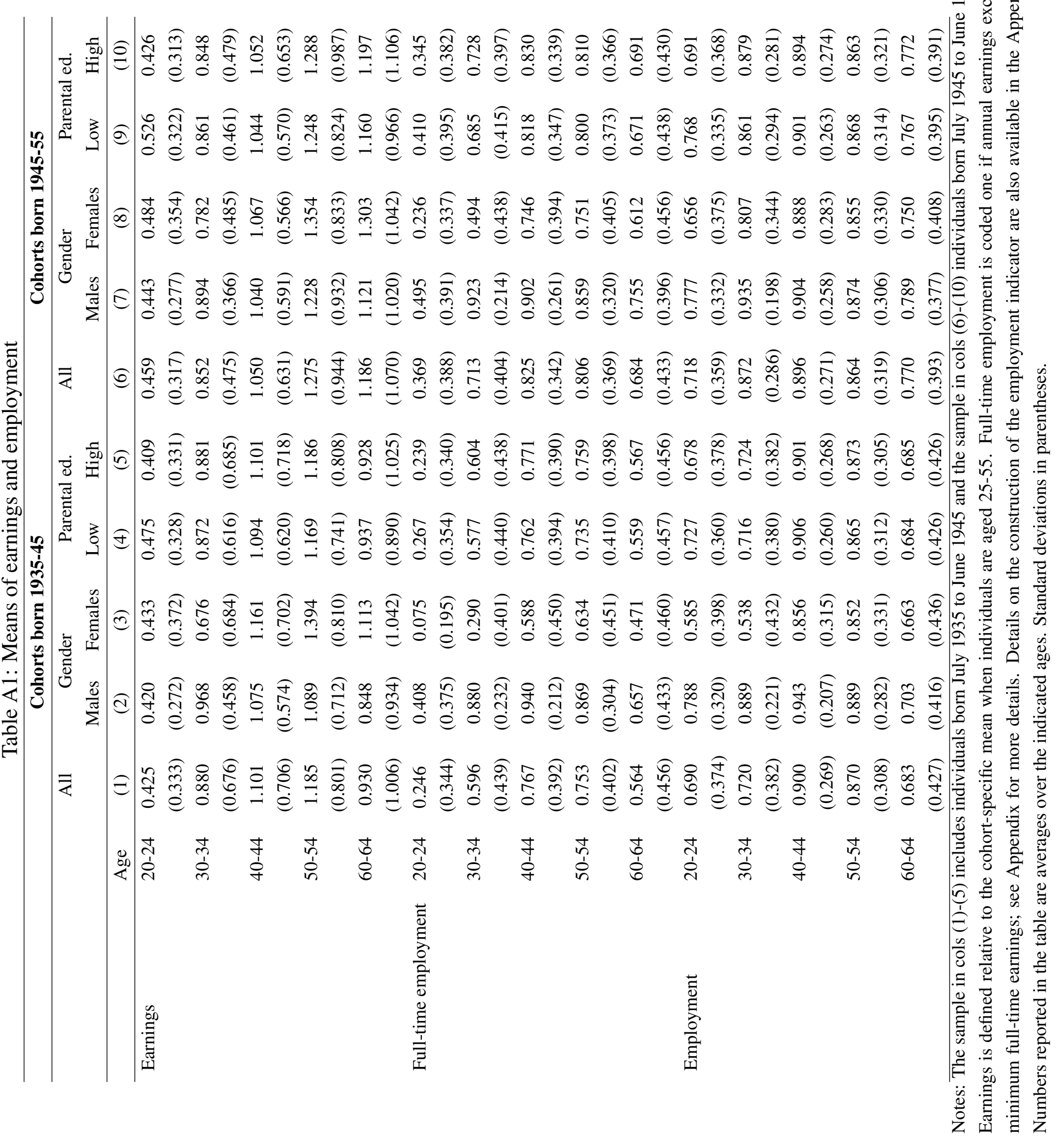




\section{Construction of key variables}

Employment indicators We construct the employment indicators by the mapping from the cross-sectional distribution of wages and earnings in 2009. We divide the data into "cells" on the basis of gender ( 2 categories), education (5 categories), and age ( 9 categories); the combination of these categories yield 90 cells. For each cell, we calculate a "minimum wage", i.e. the wage on the 1 st percentile, and a "low wage", the wage at the 5 th percentile. Wages are reported as monthly full-time equivalent wages.

To construct the full-time employment indicator we take the minimum wage times 12 to correspond to minimum annual earnings. Then, for each cell, we calculate the earnings percentile corresponding to this minimum annual earnings threshold. Finally, for each year of observation and each cell, we define everyone earning above the minimum earnings percentile as full-time employed.

To construct the employment indicator, we calculate average earnings for everyone with wages below the 5 th percentile. Then, for each cell, we calculate the earnings percentile corresponding to this annual employment threshold. Finally, for each year of observation and each cell, we define everyone earning above this threshold percentile as employed.

Age-specific earnings Earnings data are available for 1960-66, 1968, 1970-71, 1973, 197576, 1979-80, 1982, 1985-2009. Take someone born in 1940 for instance. For this individual, earnings are observed at age 20-26, 28, 30-31, 33, 35-36, 39-40, 42, and 45-69. For an individual born 1945, earnings are available at age 16-21, 23, 25-26, 28, 30-31, 34-35, 37, 40-64. This implies that the amount of earnings information varies somewhat over cohorts and that the earnings data do not represent the true relative size of cohorts at a given age. Since there are cohort effects (see Figure 8), we would like the earnings data to represent the relative size of cohorts in the population.

In general we calculate age-specific earnings as a moving average of earnings for a particular age \pm 1 . For an age where there is no information, we use the preceding and subsequent age to fill in the blank. We only fill in blanks if there is information for a preceding and subsequent year. In a few instances we use information that is more distant than age \pm 1 . For example, an individual born in 1940 has no earnings information at age 37. For this individual we calculate earnings at age 37 as a weighted average of earnings at age 36 and earnings at age 39 , where earnings at age 39 receive lower weight since it is more distant than earnings at age 36. Using this approach we obtain earnings data for each age between the ages 21-68 for the individual born 1940 and between the age 17-63 for the individual born 1945. 
This approach smooths the estimates somewhat and ensures that each cohort gets the weight it should have if earnings information was available for the entire 1960-2009 period. Notice, however, that we do not (artificially) improve the precision of the estimates (since standard errors are clustered on the discrete values of the assignment variable). Also, the effects on the age-earnings profile have a very similar flavor if we treat the data as a standard unbalanced panel.

Assigning reform status We follow Holmlund (2007) in assigning reform status to individuals. The principal input into this calculation is the population census from 1970. In the census we whether individuals have $7,8,9$, or more than 9 years of education. We drop everyone with more than 9 years of schooling. Now, 7 years of schooling correspond to old compulsory school, 8 years of schooling correspond to "extended compulsory school", and 9 years of schooling to the comprehensive school. We define two dummy variables associated with 8 and 9 years of schooling and then collapse the data by birth parish and year of birth. Whenever the mean of any of these two dummy variables exceed 0.5 , we code the parish as having implemented the reform in question from this point and onwards.

\section{Cohort weighting in the analysis the present value of earnings}

Because of the availability of earnings data, all cohorts are not observed throughout their careers. For the oldest cohorts, we miss the young ages and thus underrepresent the cost of entering school later; for the younger cohort, we miss the ages close to retirement and, therefore, the gains of starting later. To deal with this problem we place additional weight on the cohorts observed during the ages that are missing for some cohorts.

To be concrete, consider earnings at age 18. Earnings at age 18 is observed starting with the 1943 cohort. $^{23}$ Therefore, we observe earnings at this age for 12 of the 20 cohorts. To adequately represent earnings at age 18 in the present value calculation, we place the weight 20/12 on earnings observations at age 18. Analogously, earnings at age 19 is available starting with the 1942 cohort, and thus observed for 13 of the 20 cohorts. Earnings observations at age 19 thus receive the weight 20/13. At the other end of the age spectrum, earnings at age 55 is unobserved for 1 cohort (the 1954 cohort). Earnings observations at age 55 thus receive the weight 20/19. In general we weight earnings at a particular age with \#cohorts/(\#non-missing cohorts at that age).

\footnotetext{
${ }^{23}$ Remember that we construct age-specific earnings by averaging earnings over three ages (age \pm 1$)$. Therefore we loose the first and the last observation for each cohort.
} 
Figure A2. Number of births (left) and parental education (right) by day of birth $(5,15,25)$
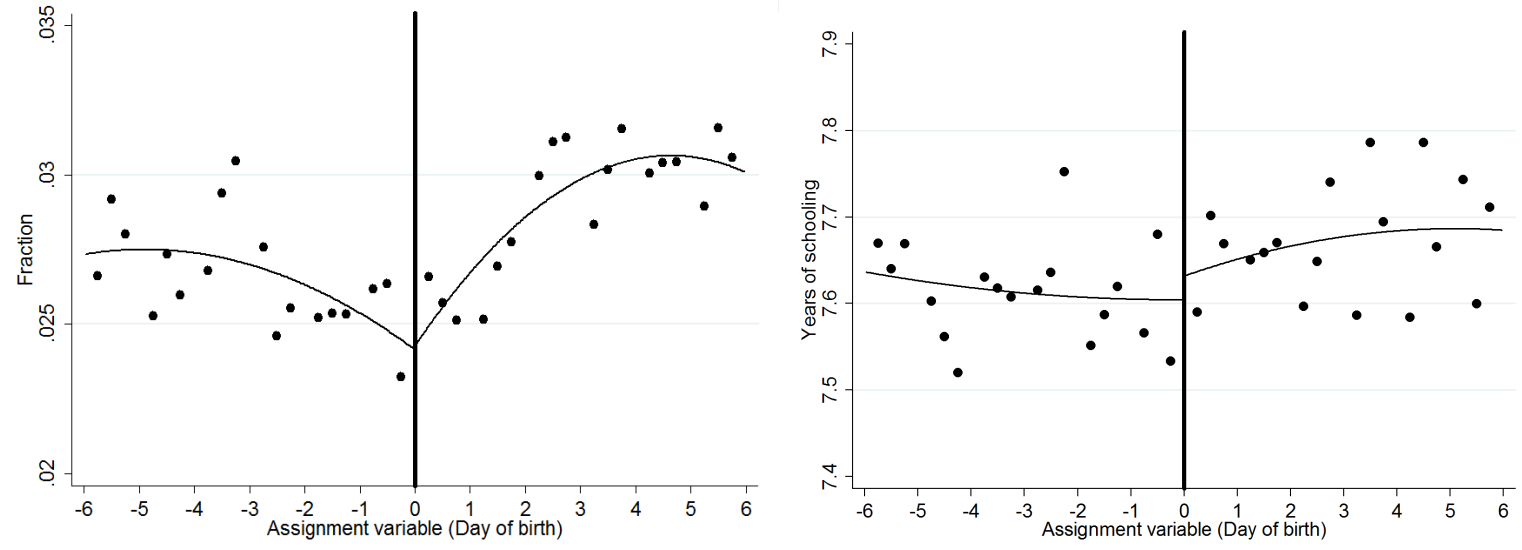

Note: The graph on the left shows the distribution of births by birthday $(5,15,25)$ among native men who are born between July 1935 and June 1940. The graph on the right shows parental years of schooling by birthday $(5,15,25)$ for the same population. Parental education is defined as the maximum of the education of the father and the mother. Discontinuity at cut-off (left): 0.00013 (standard error: 0.00081). Discontinuity at cut-off (right): 0.0298 (standard error: 0.0631). The solid vertical line depicts the school-entry cut-off. Regression lines are 2nd order polynomials fitted separately to the data on both sides of the cut-off. Throughout we control for cohort. In the figure on the right we control for educational reform (see section 2) as well. Controlling for educational reform is not necessary (without the controls the discontinuity estimate is 0.0137 (standard error: 0.0579)) but consistent with our baseline specification.

\section{Further evidence on the validity of the RD-design}

Our main data only contains information on birth month. However, the earnings data during 1960-66 include information on birthday for those born on the 5th, 15 th, or the 25 th. Individuals are included in the earnings data if they have ever worked during 1960-66. For men born between July 1935 and June 1940, 99.2-99.7\% of the target population are included in the earnings data. For men in later cohorts and women, coverage is substantially lower. Here, we present additional evidence on the validity of the RD-design using these data focusing on men born 1935-40. Since gender is random, the focus on men should be inconsequential.

Figure A2 presents the evidence. The left-hand panel (number of births) is analogous to Figure 1 and the right-hand panel (parental schooling) is analogous to Figure 2. Both panels show that there is no shift around the discontinuity when we use the more detailed information on day of birth. We have also run the McCrary (2008) test on the data shown to the left. The estimated shift in the log of the density is 0.0108 with a standard error of 0.0451 (the estimate was obtained using a bandwidth of 1 and a smoothing parameter of 3 ). 